\title{
Diagnóstico y dinámica poblacional de nematodos fitoparásitos en dos sistemas de cultivos de piña en Costa Rica
}

Diagnostic of plant parasitic nematodes and its population dynamics in two pineapple cultivation systems in Costa Rica

Tomas de Jesús Guzmán-Hernández' Joaquín Durán-Mora'

Wayner Montero-Carmona'

Henry Vargas-Céspedes'

Zulay Castro-jiménez'

Dinia Estela Carvajal-Vargas'

Dany León-Arias'

Fecha de recepción: 24 de abril del 2013

Fecha de aprobación: 27 de octubre del 2013

Guzmán-Hernández,T; Durán-Mora, J; MonteroCarmona, W; Vargas-Céspedes, H; Castro-Jiménez, Z; Carvajal-Vragas, D; León-Arias, D. Diagnóstico y dinámica poblacional de nematodos fitoparásitos en dos sistemas de cultivos de piña en Costa Rica. Tecnología en Marcha.Vol. 27, № 2. Pág 58-8I 


\section{Palabras clave}

Piña (Ananas comosus, var comosus); híbrido MD2; el diagnóstico; dinámica de población; nematodos; modelos matemáticos.

\section{Resumen}

La presente investigación determinó la presencia de géneros, densidad de población y dinámica poblacional de nematodos fitoparásitos en plantaciones de piña (Ananas comosus, var. comosus) en dos sistemas de cultivos en Costa Rica, período 2006-2008.

El estudio comprendió un diagnóstico a nivel de suelo y raíz en plantas de dos a doce meses de edad que permitiera la determinación de la dinámica poblacional de los nematodos en los diferentes lotes cultivados de piña, durante el lapso de tiempo señalado en sistemas de cultivos convencionales y orgánicos en las regiones Huetar Norte y Huetar Atlántica de Costa Rica. Se seleccionaron lotes comerciales, los cuales fueron muestreados una vez al mes durante febrero a diciembre en los años 2006-2008. Se caracterizaron y cuantificaron los géneros de nematodos encontrados.

El diagnóstico permitió la identificación de siete géneros a nivel de suelo: Helicotylenchus spp., Meloidogyne spp., Pratylenchus spp., Tylenchus, Tylenchorhychus, nematodos depredadores y de vida libre, donde el género Helicotylenchus spp. el que se indentificó con más frecuencia. La mayor población de nematodos fitoparásitos fue observada a nivel de suelo y correspondió a los géneros Pratylenchus spp. y Helicotylenchus spp.

Los nematodos más frecuentemente observados en raíces de plantas de piña bajo técnicas orgánicas fueron: Criconemella spp., Helicotylenchus spp., Pratylenchus spp.; en el suelo se presentaron Helicotylenchus spp., y Pratylenchus spp., con frecuencias del 100\%. En raíz y suelo de plantas de piña bajo técnicas convencionales el género Helicotylenchus spp. ,fue el más frecuente. El género Pratylenchus spp. presentó la densidad poblacional promedio más alta en la raíz en sistemas orgánicos y convencionales con 1.009,83 y 1.075,22 ind/ I $00 \mathrm{~g}$ de raíz, respectivamente.

En las áreas de manejo orgánico se presentó una mayor diversidad de géneros de nematodos en la raíz de la piña, los nueve géneros fitoparásitos que se observaron fueron: Pratylenchus spp., Helicotylenchus spp., Meloidogyne spp., Haplolaimus spp., Tylenchus spp., Criconemella spp. y Xiphinema spp. y nematodos de vida libre, en comparación con muestras de raíz de plantas con manejo convencional donde se presentaron seis géneros fitoparásitos (Pratylenchus spp., Helicotylenchus spp., Nacobus spp., Tylenchus spp., Meloidogyne spp.,Criconemella spp.) y nematodos de Vida Libre.

A nivel de raíces, los géneros de nematodos identificados fueron cinco: Helicotylenchus spp., Meloidogyne spp., Pratylenchus spp., Rotylenchus spp. y nematodos de vida libre. La mayor población de nematodos fitoparásitos observada a nivel de raíz corresponde a los géneros Helicotylenchus spp. con y Pratylenchus spp.

Con manejo convencional se presentaron siete géneros de nematodos fitoparásitos (Pratylenchus spp., Helicotylenchus spp., Tylenchus spp., Meloidogyne spp., Criconemella spp., Haplolaimus spp.y Tylenchorhynchus spp. y nematodos de vida libre, mientras que en suelo de plantas cultivado con manejo orgánico se presentaron seis géneros fitoparásitos Pratylenchus spp., Helicotylenchus spp., Tylenchus spp., Meloidogyne spp., Criconemella spp. y Rotylenchus spp. y nematodos de Vida libre.

\section{Key words}

Pinneaple Ananas comosus; hybrid MD2; diagnostic; population dinamic; nematodes; mathematical models.

\footnotetext{
Abstract

The presence of genera, population density and population dynamics of plant parasitic nematodes in two pineapple plantations (Ananas comosus var. Comosus) located in Costa Rica, were determined.

The study included the evaluation of soil and roots in plants of two to twelve months with the objective of determine the population dynamics of nematodes in different plots of plantations of pineapple, in conventional and organic farming systems in the Región Huetar Norte and Región Huetar Atlántica of Costa Rica. Commercial lots were carefully chosen, and sampled monthly in the course of February to December in the years 2006, 2007 and 2008.
} 
Every sample was processed for characterization and quantification of plant parasitic nematodes.

The diagnosis allowed the identification of seven genera of plant parasitic nematodes present in soil samples: Helicotylenchus spp, Meloidogyne spp, Pratylenchus spp, Tylenchus, Tylenchorhychus. At the same time it was observed free living nematodes. Helicotylenchus spp was the most frequently detected nematode. Pratylenchus spp. and Helicotylenchus spp showed the highest populations in soil samples.

Nematodes more frequently observed in roots of pineapple plants under organic system were Criconemella spp, Helicotylenchus spp and Pratylenchus spp. While Helicotylenchus spp. and Pratylenchus spp. were observed in the 100\% of the soil samples. In roots and soil of pineapple plants under conventional system, Helicotylenchus spp. was the most frequently nematode detected. The genus Pratylenchus spp. presented the highest population density in the root samples, with an average of 1009.83 individuals/ I00 $\mathrm{g}$ of root in the organic systems, and 1075.22 individuals/l $00 \mathrm{~g}$ of root in the conventional systems.

In the organic managed plantations it was observed a greater diversity of nematodes, nine plant parasitic genera were observed: Pratylenchus spp, Helicotylenchus spp, Meloidogyne spp, Hoplolaimus spp, Tylenchus spp, Criconemella spp. and Xiphinema spp. and free-living nematodes too. Whereas in the conventional managed plantations six plant parasitic genera were observed: Pratylenchus spp., Helicotylenchus spp., Nacobus spp., Tylenchus spp., Meloidogyne spp., Criconemella spp. and free living nematodes too.

In the root samples, nematode genera identified were five: Helicotylenchus spp, Meloidogyne spp, Pratylenchus spp, Rotylenchus spp. and free-living nematodes. The highest population of plant parasitic nematodes observed in root samples corresponds to the genera Helicotylenchus spp. and Pratylenchus spp.

In conventional managed plantations seven genera of plant parasitic nematodes were observed in soil samples: Pratylenchus spp., Helicotylenchus spp., Tylenchus spp., Meloidogyne spp., Criconemella spp., Hoplolaimus spp. Tylenchorhynchus spp. and free-living nematodes, while in soil samples of organic managed plantations six genera of plant parasitic nematodes were observed Pratylenchus spp., Helicotylenchus spp., Tylenchus spp., Meloidogyne spp., Criconemella spp. Rotylenchus spp. and free living nematodes.

\section{Introducción}

La piña (Ananas comosus, var. comosus) es una fruta de alto valor comercial en Costa Rica, que representa el 39\% de las exportaciones de piña fresca en el mundo (Fondo para el Desarrollo Integral de la piña y Mitigación de Impacto Ambiental 2005). Los principales mercados son Estados Unidos y Europa en la que el híbrido MD-2 ha tenido una gran aceptación por su agradable sabor, aroma, color y apariencia de la pulpa (Castro, 2004). Este cultivo se ha convertido en un pilar del desarrollo económico y social del país, constituyendo una importante fuente de divisas y empleo en el sector agrícola. Esto se debe a su producción anual, la disponibilidad de suelos aptos para el cultivo, condiciones climáticas favorables e infraestructura apropiada, además del desarrollo e implementación de cambios positivos que se han dado en la preparación de suelos, control de plagas, manejo de la plantación y tecnologías postcosecha, entre otros factores. Todos estos aspectos han estimulado al sector para continuar sus esfuerzos de mejoramiento e incremento de nuevas áreas y nuevas tecnologías para el cultivo de piña.

Los niveles de exportaciones actuales mantienen a Costa Rica como el primer país de exportación de piña fresca a nivel mundial, generando divisas con un valor FOB US\$665,9I millones para el año 20 I 0, según PROCOMER (200 I ). A su vez, el sector piñero genera cerca de 27500 empleos directos y II0 000 indirectos para el desarrollo, manejo y comercialización de más de 40000 hectáreas cultivadas, lo que lo constituye en una de las principales actividades generadoras de fuentes de trabajo (Chaves 20I I).

De acuerdo con Castro (2000), a partir del cultivo comercial de variedades como Monte Lirio (criollo) y en paralelo con a la introducción en Costa Rica de la variedad Cayena, la Champaka F-I54, y el híbrido MD-2, se fue generado un importante desarrollo tecnológico de la producción de la piña por la aplicación de nuevas técnicas de producción, el uso de maquinaria y equipo especializado.

El desarrollo socioeconómico del entorno inmediato de las zonas donde se ubican las empresas 
y productores comerciales, ha tenido un auge, con el surgimiento de otras actividades sociales y productivas que complementan la producción de piña, que se traduce en el desarrollo de una producción combinada, con el apoyo de mano de obra calificada, contribuyendo así al desarrollo social y económico, de las zonas productoras y del país.

La literatura sobre problemas fitosanitarios de la piña en Costa Rica, con frecuencia hace referencia a los principales patógenos de cultivo. Castro (2000), menciona Cochinilla harinosa (Dysmicoccus brevipes), Sinfilidos (Scutigerella inmaculata), Tecla (Strymon basilides), Caracoles (Opeas pumilum), roedores (Signodon hispidus), Elaphria (Elaphria nucicolora) y hormigas (Atta sp.); sin embargo pocos investigadores y productores mencionan los nematodos como un problema cotidiano. Según Castaño (1994), raramente cualquier cultivo se encuentra libre de nematodos fitoparásitos y su presencia generalmente pasa desapercibida debido a su tamaño microscópico y posición protegida en el suelo.

La presencia de poblaciones iniciales de nematodos en plantaciones antes de sembrar en cultivos anuales, usualmente tienen relación con los rendimientos de las cosechas (Schomaker y Been 1998 citado por Hernández, 1998).

Portal motivo, el Centro de Investigación y Desarrollo para Agricultura Sostenible del Trópico Húmedo (CIDASTH) y la Escuela de Agronomía del Instituto Tecnológico de Costa Rica (ITCR) han orientado recursos del proyecto "Prospección, caracterización y evaluación de las relaciones de organismos benéficos para el control de nematodos patógenos en condiciones del trópico", enfocado en el cultivo de piña, para determinar la condición actual de las plantaciones de las regiones Huetar Norte y Atlántica en dos sistemas de cultivos diferentes, para definir con precisión la incidencia de los nematodos fitoparásitos y la dinámica de la población de nematodos asociados al cultivo de piña híbrido MD-2 en plantaciones manejadas con técnicas de producción orgánica y producción convencional.

\section{Materiales y metodos}

la presente investigación se desarrolló en dos ambientes: plantación convencional y orgánica, ambas del hibrido MD-2, cultivadas en dos regiones, la región Huetar Norte y la Atlántica. Las muestras de suelo y raíz de ambas plantaciones fueron extraídas de las fincas Corsicana y Transunión, la primera ubicada en Llano Grande y la otra en Pueblo Nuevo, Sarapiquí, Heredia. En la región Huetar Norte se trabajó en la Finca El Tremedal, ubicada en Venecia de San Carlos, Alajuela. Los análisis de nematodos se realizaron en el Laboratorio de Nematología del Instituto Tecnológico de Costa Rica, Sede de San Carlos en Santa Clara.

La Finca Corsicana se encuentra geográficamente situada entre las coordenadas $10^{\circ} 26^{\prime} 40^{\prime \prime}$ - $08^{\circ} 28^{\prime}$

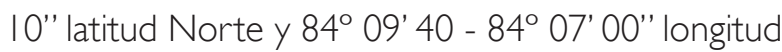
Este, a una altitud aproximada de 100- I 50 metros sobre el nivel del mar (msnm), en terrenos regularmente planos con pequeñas depresiones junto a las quebradas y pequeñas lagunas, con una vegetación principalmente riparia, parches de bosques y algunas tierras reforestadas.

La finca Transunión se encuentra situada a $10^{\circ} 29^{\prime}$ 23" latitud Norte y 8356' I 5" longitud este, a una altitud aproximada de 100 y $150 \mathrm{msnm}$.

La finca El Tremedal, se encuentra situada a $10^{\circ} 26$ latitud Norte y $84^{\circ}$ I 5 longitud Este, a una altitud aproximada de $320 \mathrm{msnm}$. La humedad relativa promedio es de $80 \%$, las precipitaciones oscilan entre 3.500 y $4.000 \mathrm{~mm}$ al año, y la temperatura promedio es de $24^{\circ} \mathrm{C}$.

Periodo de ejecución de la investigación.

La investigación se llevó a cabo en etapas simultáneas en el campo y en el laboratorio, durante el período comprendido entre marzo del 2006 y hasta el mes de octubre del 2008, realizando muestreos sistemáticos cada treinta días en cada lugar.

Actividades de cultivo aplicadas en la agricultura convencional

Se aplicó un herbicida postemergente, seguido de dos pases consecutivos de rastra y la aplicación de encalado (dolomita), otro pase de rastra y uno de subsolador. Las plantas se establecieron en el sistema de siembra de camas en doble hilera, mediante el sistema en tresbolillo, con I,12 m entre centro y centro de camas, 0,48 m entre cada par de hileras, 0,25 $\mathrm{m}$ entre plantas, para una densidad de siembra de 68000 plantas/ha. Se sembró semilla hijo tipo guía de 750 gramos, tratada con Diazinon 
(Diazinon) y Aliette (Fosetil Aluminio). Se aplicó fertilizante granular a razón de $30 \mathrm{~kg} / \mathrm{ha}$, y nematicida granulado Mocap 15 (ingrediente activo Etoprofos: 0-etil S,S-dipropil fosforoditioato).

Actividades de cultivo aplicadas en la alternativa orgánica

El área en estudio fue mecanizada mediante un pase de rastra incorporando los restos del cultivo anterior, seguidamente se sembró mucuna (Mucuna pruivirens), la cual permaneció cultivada por tres meses. La mucuna se incorporó al suelo mediante dos pases del triturador y el terreno se dejó en descanso por 45 días. Seguidamente se realizaron dos pases de rastra separados por una aplicación de cal (dolomita) y un pase de subsolador. Previo a la colocación de la cobertura de polietileno negro se realizó el encamado y sobre las camas se aplicó harina de sangre $(220 \mathrm{~kg} / \mathrm{ha})$. Las plantas se establecieron bajo el método de siembra de camas, cultivadas a doble hilera mediante el sistema en tresbolillo con distanciamientos de 1,2 metros entre centro y centro de cama, 0,45 a 0,5 entre cada par de hileras y 0,3 metros entre plantas, para una densidad de siembra de 66443 plantas/ha. El tipo de semilla utilizada varió según cada bloque (guía y basal), no se realizó tratamiento para el control de enfermedades y plagas en la semilla. La inducción floral se realizó a los diez meses de edad de plantación.

\section{Muestreo por tipo de producción} convencional y orgánica

Los muestreos se realizaron de manera sistemática según la ubicación de los lotes cultivados, los cuales fueron seleccionados previamente. Se utilizaron cinco plantas, seleccionadas en zigzag dentro de cada lote, para formar una muestra compuesta de cada uno de ellos.

Se obtuvo una muestra compuesta como resultado de cinco submuestras tomadas en el área equivalente al lote seleccionado previamente (figura I). En cada punto de muestreo se hizo la extracción de una planta completa, se cortó la parte radical de la misma y se recolectó el suelo correspondiente a 20 $\mathrm{cm}$ de profundidad. El suelo y la raíz se colocaron en bolsas plásticas y se trasladaron al laboratorio.
El primer muestreo se realizó 30 días después de la siembra (dds) y los subsecuentes en periodos similares de 30 días hasta el duodécimo mes. Los muestreos se realizaron simultáneamente en los dos sistemas de producción.

En el cuadro I se identifican los bloques seleccionados, el área y la densidad poblacional por plantación (orgánica y convencional).

Procedimiento de la extracción de nematodos en el laboratorio

La extracción de los nematodos se realizó por tipo de muestra (suelo y raíz) y los métodos aplicados y sus procedimientos fueron los siguientes:

\section{Embudo de Baermann para la} obtención de nematodos en suelo

La extracción de nematodos en suelo se realizó mediante la técnica del embudo de Baermann modificado (Esquivel, 2005). Este método consistió en pesar $25 \mathrm{~g}$ de suelo homogeneizado después de eliminar otros desechos. Las muestras de suelo se colocaron en un papel filtro, sostenido por un embudo con una manguera adherida a la parte inferior, en el cual se colocó un vial para recoger los nematodos. A cada muestra se le adicionó agua hasta $1 \mathrm{~cm}$ por encima de la parte superior del embudo y se dejó reposar durante 72 horas. Después de este periodo se recogió el vial que contenía aproximadamente $5 \mathrm{ml}$ de solución, se homogeneizó y se tomó una alícuota de $3 \mathrm{ml}$ para el conteo e identificación en el microscopio invertido.

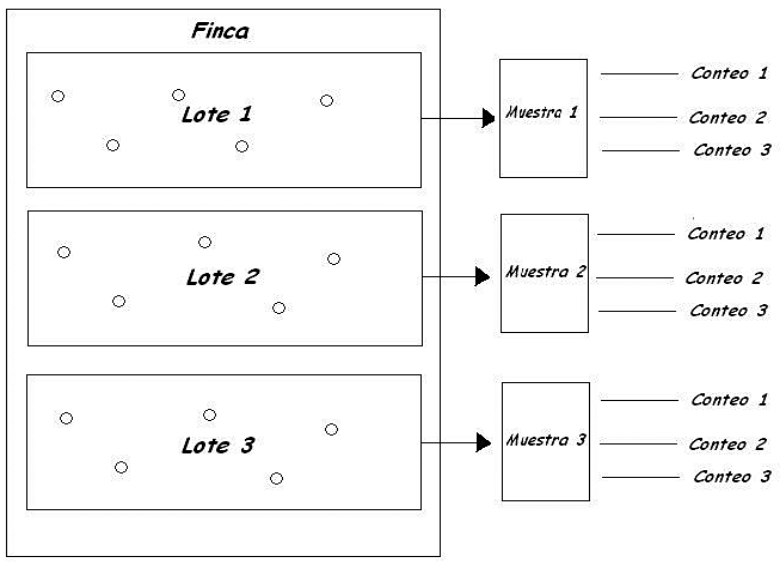

Figura I. Esquema de la toma de muestras en cada lote. 
Cuadro I. Identificación de área experimental por finca y tipo de plantación.

\begin{tabular}{|c|c|c|c|}
\hline $\begin{array}{l}\text { Tipo de plantación/ } \\
\text { Identificación de Finca }\end{array}$ & Lote comercial $\mathrm{N}^{\circ}$ & Área (hectáreas) & Número de plantas/ha \\
\hline \multirow{6}{*}{ Orgánica (Corsicana) } & 75 & 0,44 & 29505 \\
\hline & 75 & 0,33 & 22070 \\
\hline & 79 & 0,59 & 39288 \\
\hline & 81 & 0,58 & 38284 \\
\hline & 85 & 0,43 & 28632 \\
\hline & 86 & 0,43 & 28632 \\
\hline \multirow{7}{*}{ Convencional (Transunión) } & 3 & 0,31 & 21080 \\
\hline & 8 & 0,20 & 13600 \\
\hline & 9 & 0,45 & 30600 \\
\hline & 18 & 0,36 & 24480 \\
\hline & 20 & 0,28 & 19040 \\
\hline & 24 & 0,28 & 19040 \\
\hline & 25 & 0,28 & 19040 \\
\hline \multirow{11}{*}{ Convencional (Tremedal) } & 3 & 0,13 & 98000 \\
\hline & 9 & 0,15 & 11400 \\
\hline & 10 & 0,14 & 10640 \\
\hline & 14 & 0,13 & 98000 \\
\hline & 15 & 0,17 & 12920 \\
\hline & 16 & 0,18 & 10000 \\
\hline & 17 & 0,13 & 98000 \\
\hline & 18 & 0,15 & 11400 \\
\hline & 22 & 0,13 & 98000 \\
\hline & 43 & 0,17 & 12920 \\
\hline & 46 & 0,15 & 12920 \\
\hline
\end{tabular}

Método de Tamizado-Centrifugado y flotación con azúcar para la obtención de nematodos en raíz

Las raíces provenientes del muestreo en el campo fueron sometidas a lavado; se cortaron y pesaron muestras de $25 \mathrm{~g}$. El método aplicado fue de centrifugado-tamizado. Cada una de las muestras fue licuada durante diez segundos a velocidad baja y cinco segundos a velocidad alta. La solución obtenida del licuado fue decantada sobre un juego de cribas superpuesto de 35, 100, 170, 400 y 500 mallas. Con la ayuda de una piseta se transfirieron los residuos retenidos en la criba de 500 mallas a tubos de ensayo. Se colocaron los tubos de ensayo en una centrifugadora. Se procedió a centrifugar por cinco minutos a 3000 rpm. Después de la centrifugación se decantaron los sobrenadantes y se agregó una solución azucarada (484 g de azúcar aforada en un litro de agua). Luego de resuspender las raíces nuevamente, se centrifugaron a la misma velocidad por tres minutos. El sobrenadante conteniendo los nematodos fue vertido sobre una criba de 500 mallas y se lavó el exceso de azúcar adherida a los nematodos con suficiente agua. Una vez enjuagada el azúcar, se recolectaron los nematodos del tamiz con la ayuda de la piseta en un vial, para proceder a su observación e identificación. Para el conteo se vertió la solución en un beaker de 100 ml y se aforó a $50 \mathrm{ml}$.

\section{Procedimiento para la cuantificación de nematodos}

El conteo de nematodos se realizó en el laboratorio en un portaobjeto especial al cual se le agregaron 
tres mililitros de solución extractora y se colocó en el microscopio para su cuantificación.

Las variables evaluadas fueron:

I. Frecuencia de nematodos en raíz y suelo por género y edad de plantación en piña orgánica y convencional.

2. Cantidad de nematodos en raíz y suelo por género y edad de plantación en piña orgánica y convencional.

3. Nematodos de vida libre.

Análisis de datos

Los datos relacionados con la cantidad de nematodos por género y edad de plantación, fueron analizados por medio de la estadística descriptiva y análisis de varianza factorial utilizando la media y frecuencia en varios paquetes estadísticos, entre ellos, ajustes de curvas y SPSS (Statistical Package for the Social Sciences).

\section{Resultados y discusión.}

la identificación de los nematodos que se encontraron en las fincas orgánicas y convencionales en Costa Rica en las zonas analizadas se observa en los cuadros 2 y 3.

Dinámica de la población y frecuencia de nematodos en raíz y suelo en las plantaciones de piña orgánica, en la finca Corsicana en Sarapiquí.

\section{Frecuencia de los nematodos en las raíces}

Se destacó la presencia de los géneros de Criconemella spp., Helicotylenchus spp., Pratylenchus spp. y nematodos de vida libre, con un 100\% (figura 2).

En el caso del nematodo Criconemella spp. se ha considerado que es un parásito de la piña de importancia económica (Sasser 1989) por la transmisión de virus. Según Valiente, citado por Hernández (1998), en el caso del Helicotylenchus spp. es un nematodo ectoparásito, que puede actuar como endoparásito migratorio, que completa su ciclo en la raíz, lo que explica su comportamiento tanto en la raíz como en el suelo. Pratylenchus spp. se le llama el nematodo de la lesión de la raíz (Godfrey 1929 citado por Luc et al. 2005); se trata de un nematodo endoparásito migratorio, que normalmente se puede observar dentro de las raíces y se alimentan de ellas antes de emigrar (Costa, Gandoy citado por Hernández y Ortega, 1998, citado por Roman Godfrey 1978), Castro (2000).

El nematodo Meloidogyne spp. se presentó con una frecuencia de 71,43\% y correspondió con el tipo más frecuentemente observado en el presente estudio, ocupando el segundo lugar, a partir del tercer mes, y hasta el final del ciclo del cultivo (Jesse 1976). Este género es un endoparásito, que penetra en la raíz y coloca sus huevos en ella (Sasser 1989). Las etapas juveniles infectan las raíces principales de las plantas y después de dos o tres días permanecen

Cuadro 2. Presencia (+) o ausencia (-) de nematodos del cultivo de la piña híbrido MD-2 en fincas orgánicas y fincas convencionales. Costa Rica. 2006-2008.

\begin{tabular}{|c|c|c|c|c|}
\hline \multirow{2}{*}{ Géneros de Nematodos } & \multicolumn{2}{|c|}{100 gramos de raíz } & \multicolumn{2}{|c|}{100 gramos de suelo } \\
\cline { 2 - 5 } & Fincas orgánicas & Fincas convencionales & Fincas orgánicas & Fincas convencionales \\
\hline Pratylenchus spp. & + & + & + & + \\
\hline Helicotylenchus spp. & + & + & + & + \\
\hline Meloidogyne spp. & + & + & + & + \\
\hline Tylenchus spp. & + & + & - & + \\
\hline Criconemella spp. & + & - & - & - \\
\hline Xiphinema spp. & + & - & - & + \\
\hline Tylenchorhynchus spp. & + & - & + & + \\
\hline Hoplolaimus spp. & + & + & + & + \\
\hline Vida libre & + & & + & + \\
\hline
\end{tabular}


en ellas de manera sedentaria, Jesse (1976) y (Godfrey y Oliveira 1932, citado por Luc et al. 2005 y Romano 1978).

Tylenchus spp. se presentó en con un 42,86\% de las muestras observadas a partir del cuarto mes de edad en adelante.

Los nematodos que se observaron con menor frecuencia en muestras de raíces bajo manejo orgánico fueron: Hoplolaimus spp., limitado a las plantas de cinco meses (14,29\%), el género Tylenchorhynchus spp. se presentó con un porcentaje de frecuencia de 14,29\% en el séptimo mes y el género Xiphinema spp. con una frecuencia de $14,29 \%$ en el quinto mes de edad del cultivo.

La dinámica de los nematodos encontrados en las raíces en un sistema orgánico en la finca Corsicana y sus respectivos modelos matemáticos se muestran en las figuras 3, 4 y 5. En los tres casos, independientemente del ajuste del modelo, se puede notar que el aumento del nivel de las poblaciones de los nematodos fitoparásitos en el tiempo, es creciente.

Frecuencia de nematodos en el suelo en plantaciones de piña orgánica

En suelo bajo manejo orgánico aparecen seis géneros de nematodos parásitos y de vida libre (figura 6).

Los géneros Helicotylenchus spp. y Pratylenchus spp. fueron las más frecuentemente observadas con un porcentaje de 100\% durante los siete meses de investigación en el cultivo, según lo que indican Tarjan (1967), Tarte (1970) y Hendley, (2003).

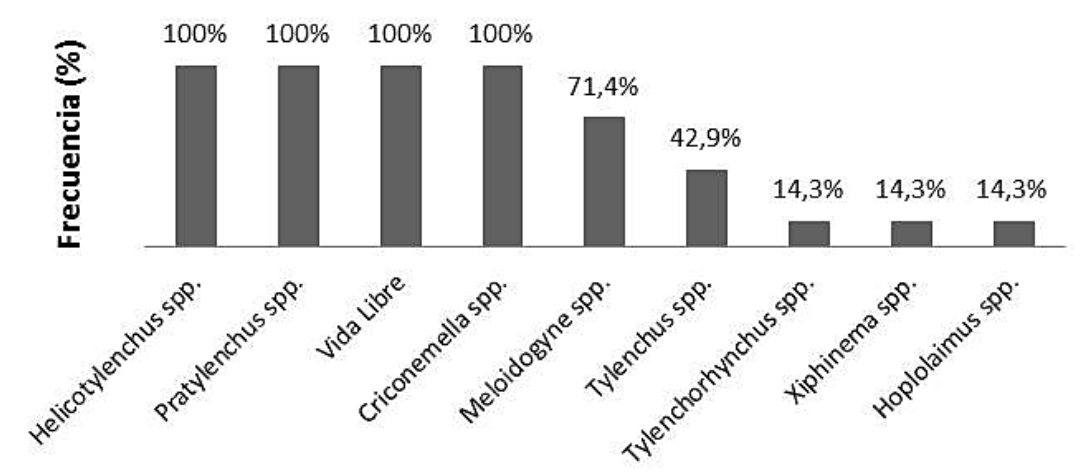

Figura 2. Frecuencia porcentual de la presencia de nematodos de cada género existente en raíces de las plantas de A. comosus híbrido MD-2 con las técnicas de producción orgánica.

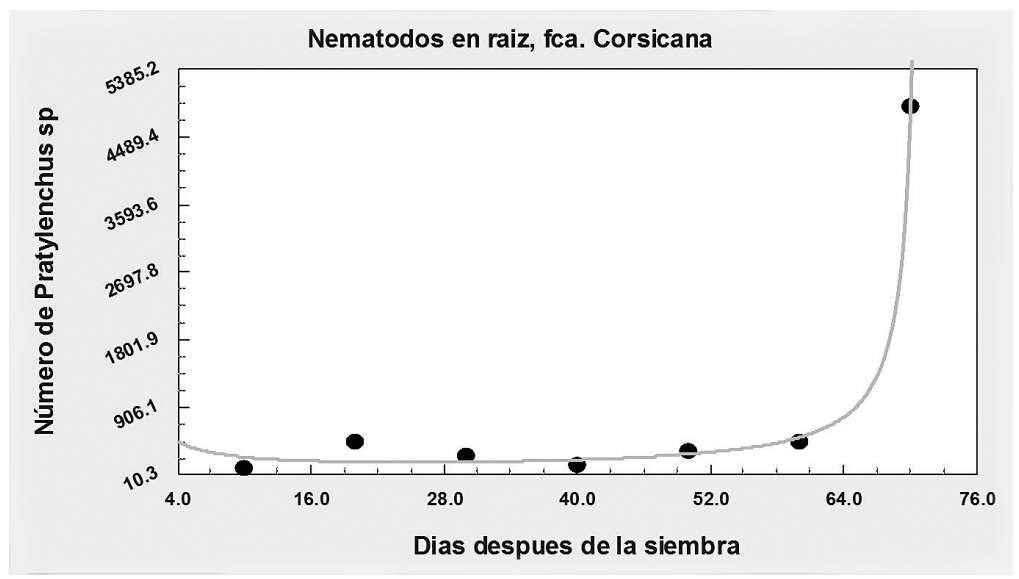

Figura 3. Ecuación racional de Pratylenchus sp. en raíz de piña orgánica (Corsicana):

$y=\frac{a+b x}{1+c x+d x^{2}} ;$ Coeficientes de los datos $: R=0.99 ; a=3860.2636 ; b=119.17991 ; c=2.2758377$. 


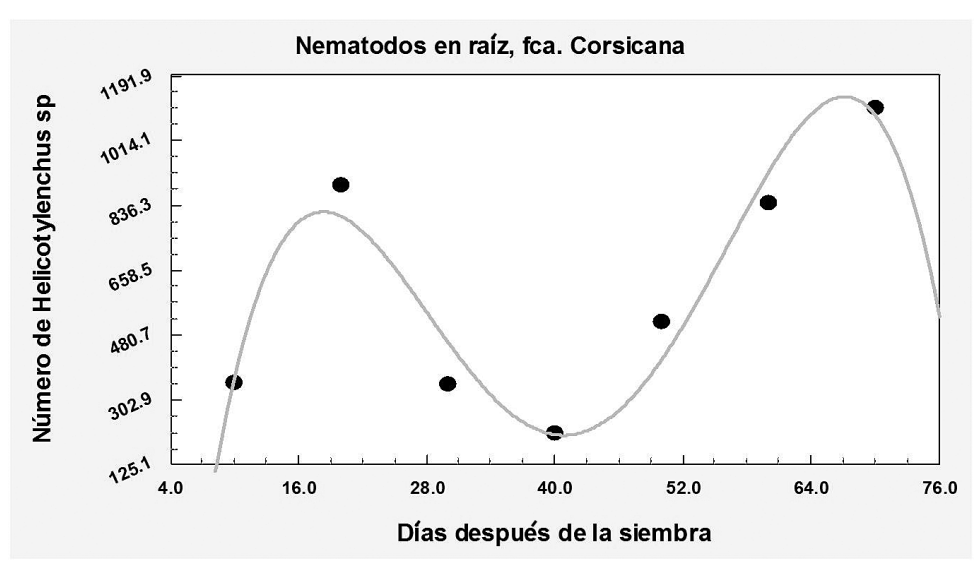

Figura 4. Ecuación polinómica de cuarto grado de Helicotylenchus sp. en raíz de piña orgánica (Corsicana): $y=a+b x+c \times 2+d x 3$, . Coeficientes de los datos: $R=0.98, a=-2230.57 \mid 4 ; b=427.87002, c=-20.149$ | 67; $d=0.36004545$; $e=-0.002|40909|$.

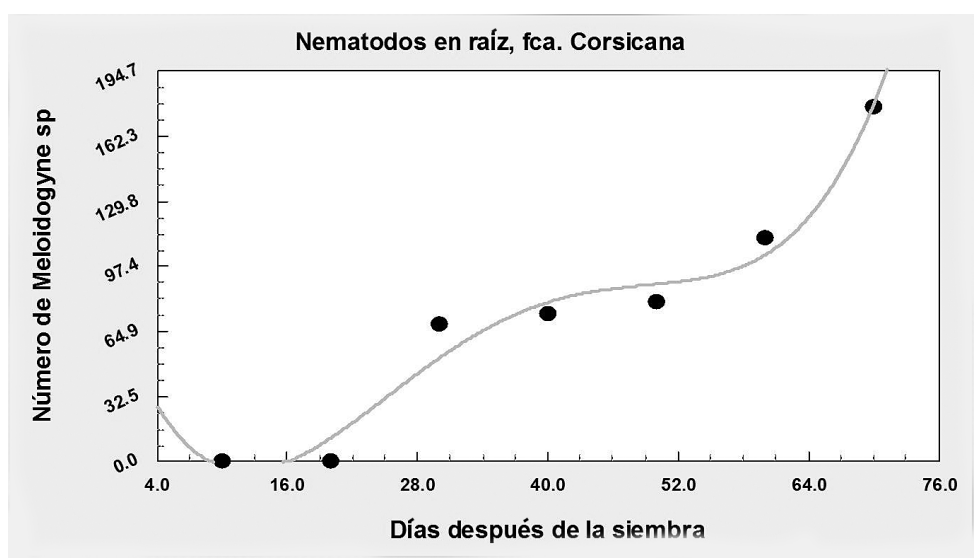

Figura 5. Ecuación polinómica de cuarto grado de Meloidogyne sp en raíz de piña orgánica (Corsicana): $y=a+b x+c x^{2}+d x^{3}$. Coeficientes de los datos: $R=0.98 ; a=75.7|4286 ; b=-| 5.574892 ; c=0.95 ; d=-0.019106061$; e =0.000 I 2878788 .

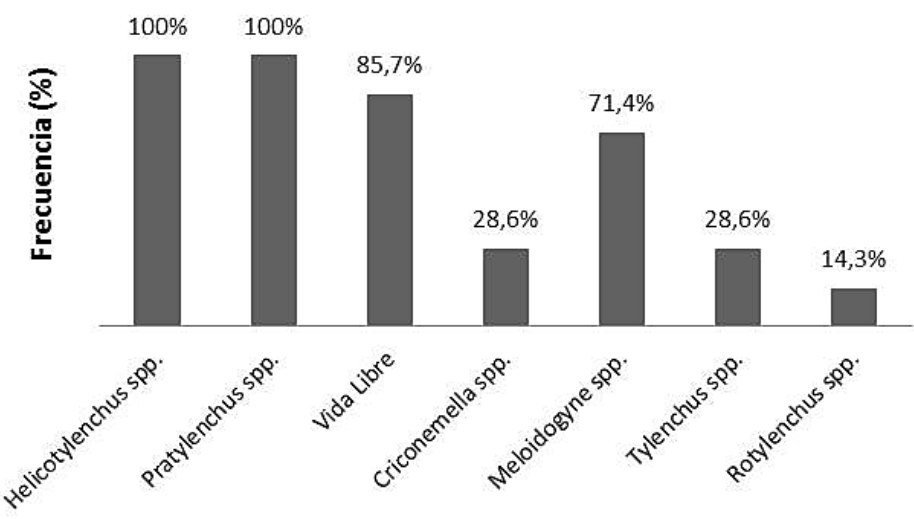

Figura 6. Porcentaje de frecuencia de la presencia de géneros existentes de nematodos en el suelo de las plantaciones de A. comosus híbrido MD-2 bajo la técnica orgánica, en la finca Corsicana, Sarapiquí. 
El nematodo Meloidogyne spp. se presentó con una frecuencia de $71,43 \%$ en el suelo.

Rotylenchus spp. fue observado únicamente en suelo con una frecuencia porcentual de 14,87\% al quinto mes de edad; según Sasser (1989), menciona que es un nematodo semiendoparásito, lo que significa que la hembra penetra la raíz para establecer un sitio de alimento permanente quedando sedentaria o inmóvil.

Con respecto al manejo orgánico los géneros Hoplolaimus spp., Tylenchorhynchus spp. y Xiphinema spp. fueron observados únicamente en muestras de raíz; contrariamente Rotylenchus spp. el cual fue observado únicamente en muestras de suelo.
En las figuras 7, 8 y 9, se pueden observar los modelos matemáticos encontrados en función de la dinámica poblacional de los nematodos en el suelo:

Al evaluar el número de nematodos totales en raíz y suelo en la finca Corsicana, se puede observar un incremento de las poblaciones en el tiempo de manera ascendente (figuras l0 y | I).

Frecuencia de nematodos en las plantaciones de piña en un sistema de cultivo convencional en la finca Transunión, Sarapiquí

\section{Nematodos en las raíces}

En las raíces de las plantaciones de piña manejadas con técnicas convencionales se identificaron seis

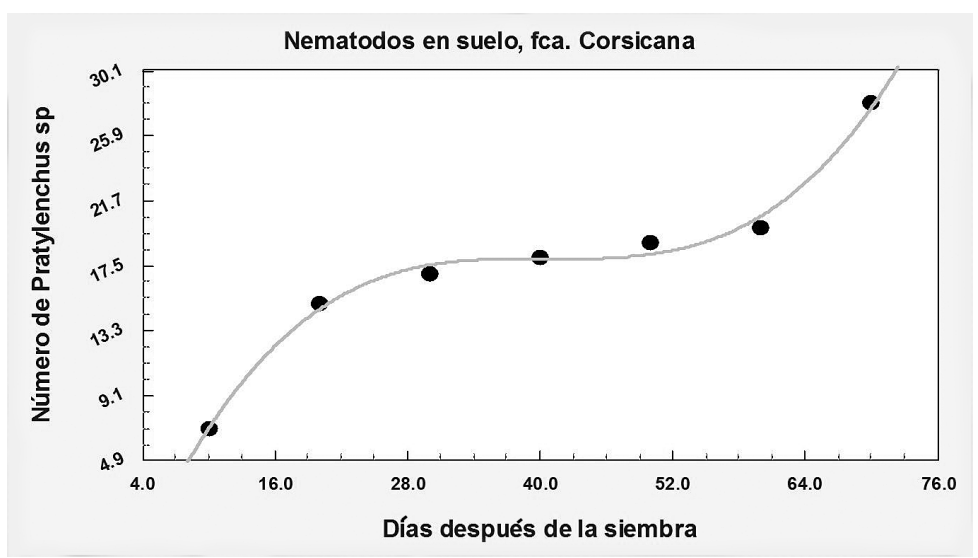

Figura 7. Pratylenchus spp. en suelo de finca orgánica (Corsicana):

Ecuación polinómica de tercer grado: $y=a+b x+c x^{2}+d x^{3}$. Coeficientes de los datos: $R=0.99 ; a=-6.57 \mid 4286$; $b=1.7261905 ; c=-0.041190476, d=0.00033333333$

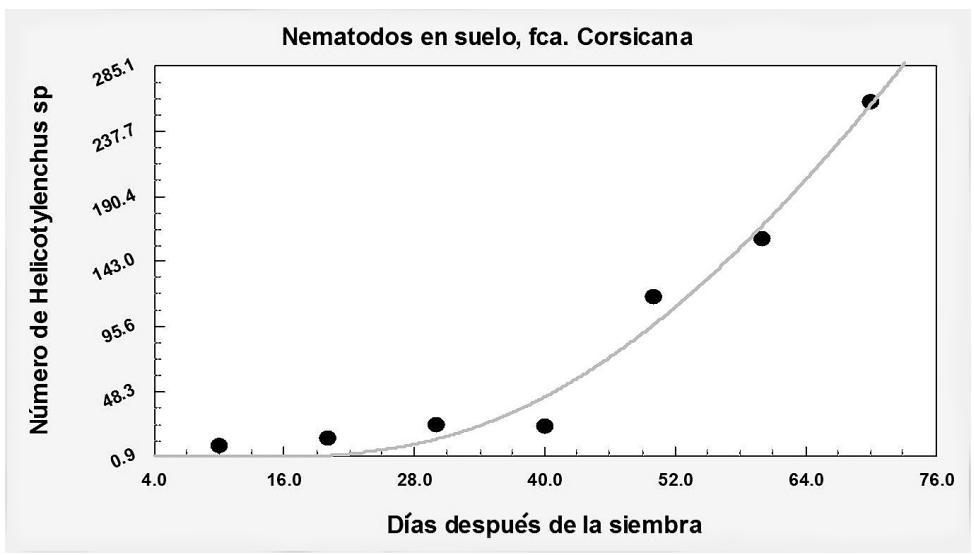

Figura 8. Helycotylenchus spp. en suelo de finca orgánica (Corsicana): Ecuación de ajuste de potencia: $y=a X b ;$ Coeficientes de los datos: $R=0.98 ; a=0.81056512 ; b=2.9662088$. 


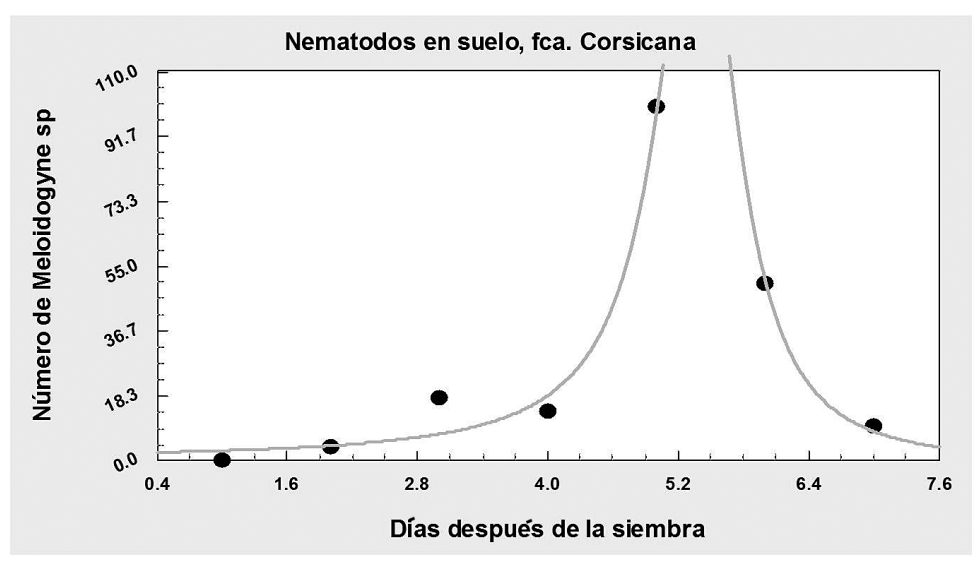

Figura 9. Meloidogyne spp en suelo de finca orgánica (Corsicana): Ecuación racional $y=(a+b x) /\left(1+c x+d x^{2}\right)$. Coeficientes de los datos: $R=0.99 ; a=2.0960$ I 85; $b=-0.18770537 ; c=-0.36880623 ; d=0.034225079$

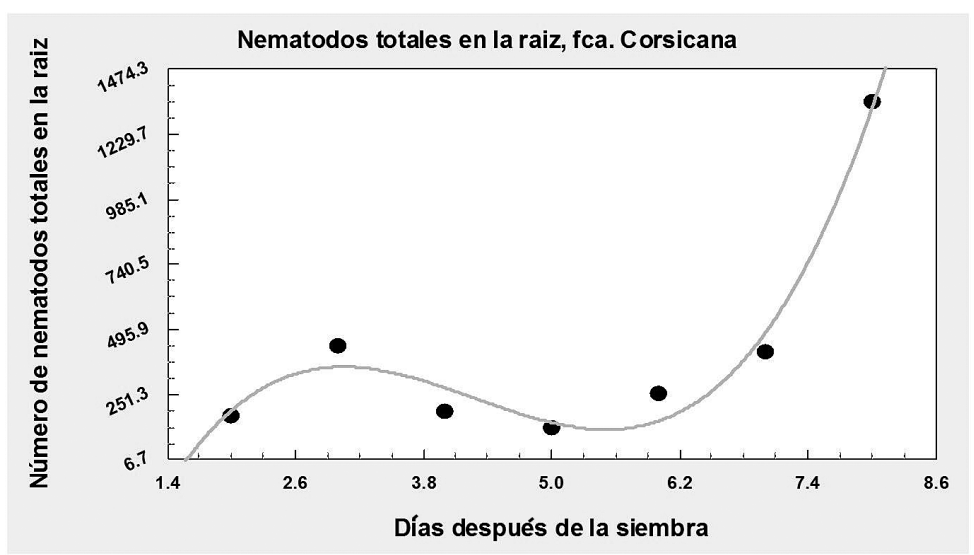

Figura 10. Nematodos totales en raíz de plantaciones orgánicas (Corsicana).

Ecuación polinomial de Tercer grado: $y=a+b x+c \times 2+d \times 3$. Coeficientes de los datos: $R=0.98 ; a=-1606.2143$; $b=|58| .4286 ; c=-403.7|429 ; d=3| .5$.

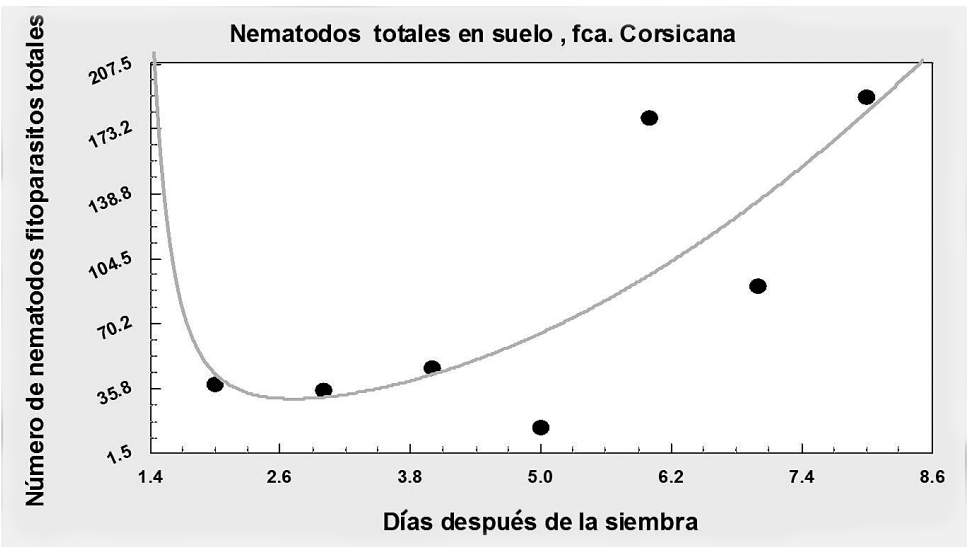

Figura I I. Nematodos totales en el suelo de plantaciones orgánicas (Corsicana).

Ecuación geométrica modificada: $Y=a x^{b / x}$. Coeficientes de los datos: $R=0.79 ; a=|3552.258 ; b=| 6.574642$. 
géneros parasitarios. En la figura 6 se muestra la frecuencia observada.

El nemátodo Helicotylenchus spp. fue observado en el 100\% de las muestras durante todos los meses, con mayor frecuencia en la raíz de la plantación convencional (Quesada y Barboza 1999).

El género Pratylenchus spp. se presentó con una frecuencia de $85,71 \%$, correspondiente al segundo género más parasitario. La frecuencia de Meloidogyne spp. fue del 7I,43\% y se observó después del tercer mes y hasta el séptimo mes de edad. Criconemella spp. se observó durante los últimos tres meses del cultivo, con una frecuencia de 42,83\%. El género Tylenchuss spp. se observó en los primeros meses y hasta el sexto mes con una frecuencia del $42,83 \%$, como se observa en la figura 12.

Dinámica de la población en las raíces y los modelos matemáticos de los principales nematodos parásitos

Los modelos matemáticos del comportamiento de los nematodos parásitos en la raíz del de la piña en un sistema convencional se pueden ver en las figuras $13,14,15$ y 16.

Frecuencia de nematodos en el suelo en la finca Transunión.

En la figura 17, se muestra el detalle de los géneros de nematodos encontrados en el suelo de las plantaciones de piña manejada con técnicas convencionales. Se han encontrado siete géneros de nematodos parásitos y de vida libre.
El género Helicotylenchus spp., fue el más frecuente, seguido por el género Pratylenchus spp. con el $71,43 \%$.

La frecuencia con que se observaron Criconemella spp., Hoplolaimus spp. y Tylenchus spp. fue del 28,6\% al final del período de cultivo. Tylenchorhynchus spp. fue el género de menor frecuencia, con 14,3\%. Tanto Hoplolaimus spp. como Tylenchorhynchus spp. solo se observaron en las muestras de suelo.

Las ecuaciones o modelos matemáticos encontrados con la dinámica poblacional de los nematodos fitoparásitos principales encontrados en el suelo en la Finca Transunión se pueden observar en las figuras 18 y 19; ellos fueron Pratylenchus spp. y Helicotylenchus spp. A pesar de que se encontró Meloidogyne spp., este parásito mostró un comportamiento de crecimiento muy bajo, por lo cual no se presenta la ecuación.

Los Nematodos totales encontrados en el suelo en la finca Transunión, se pueden observar en la figura 20.

Frecuencia de nematodos en raíz y suelo en las plantaciones de piña en sistema convencional, en San Carlos en la finca El Tremedal.

En las raíces de las plantaciones de piña manejadas con el sistema de cultivo convencional en esta finca se identificaron los nematodos Helicotylenchus spp., Meloidogyne spp., Pratylenchus spp., Rotylenchus spp. y de vida libre (figura 22). El resto de los nematodos del suelo y las raíces se comportaron de igual manera que en la Finca Transunión en las plantaciones convencionales.

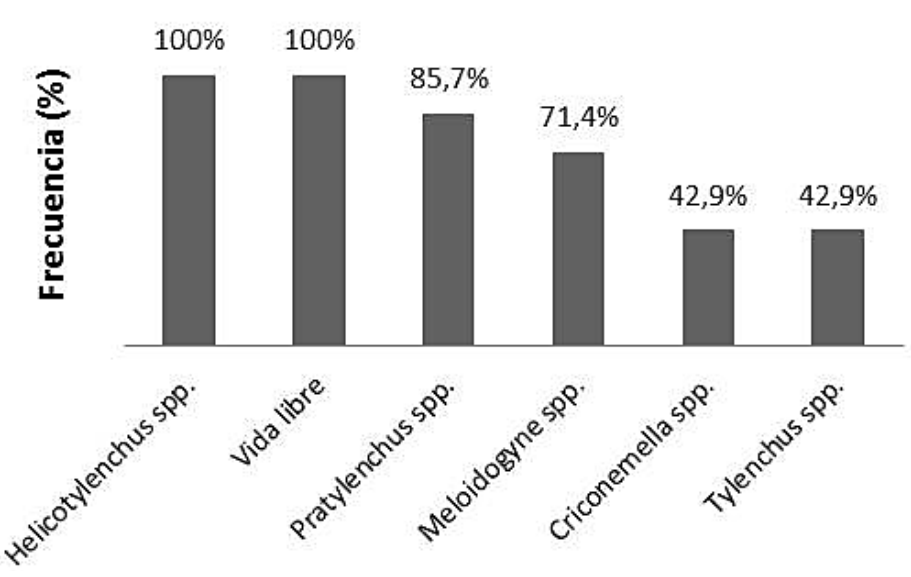

Figura 12. Porcentaje de frecuencia de la presencia por género de nematodos en plantas de A. comosus híbrido MD-2, bajo las técnicas convencionales de producción de uno a siete meses en la finca Transunión. Costa Rica 2006-2008. 


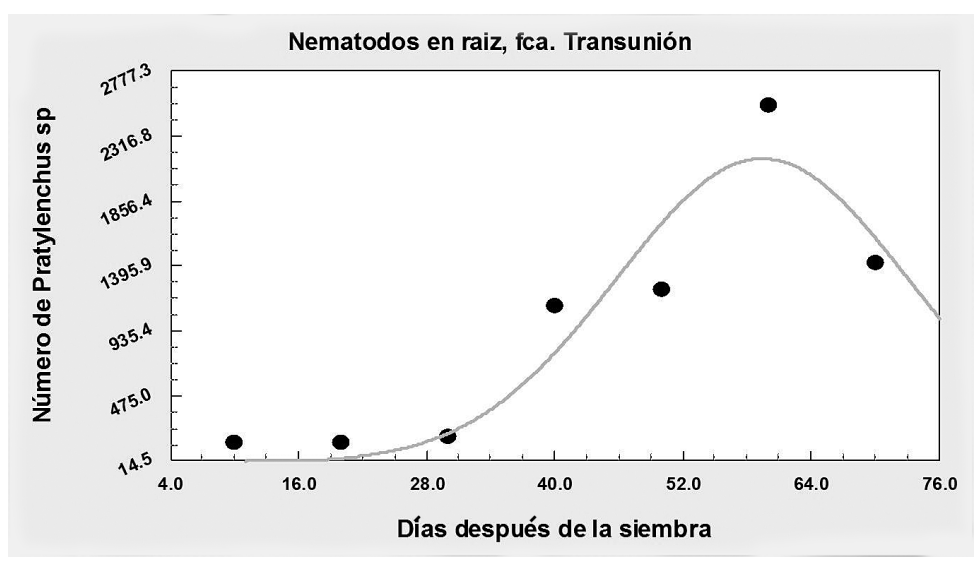

Figura 13. Pratylenchus spp. en la raíz en plantaciones convencionales (Transunión).

Ecuación de Gauss. $y=a * \exp ((-(b-x) 2) /(2 \cdot(2))$ Coeficientes de los datos: R=0.94; a=2 I 59.5454; b=59.38 I 009; $c=\mid 3.623297$

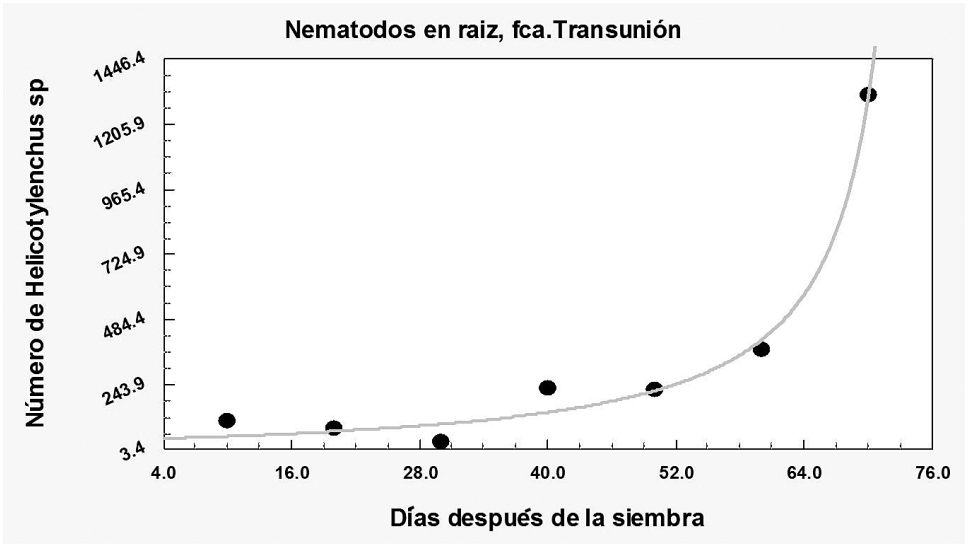

Figura 14. Helicotylenchus spp. en la raíz en plantaciones convencionales (Transunión)

Ecuación logística: $y=a /(I+b * \exp (-c x))$. Coeficientes de los datos: $R=0.99 ; a=-154.2826 ; b=-4.8$ | 80055; $c=0.0208784$

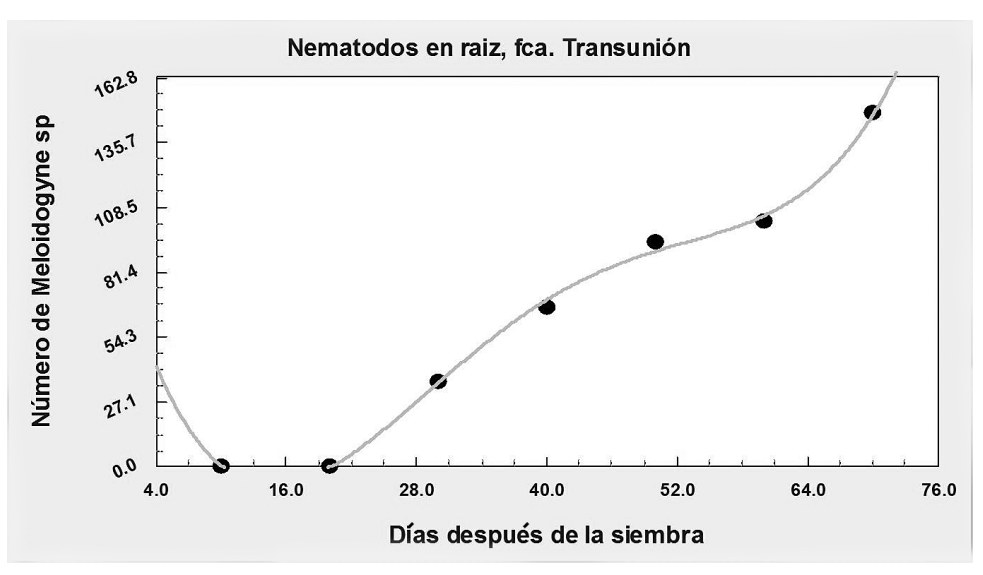

Figura 15. Meloidogyne spp. en la raíz en plantaciones convencionales (Transunión).

Ecuación polinomial de cuarto grado $y=a+b x+c \times 2+d \times 3$. Coeficientes de los datos: $R=0.99 ; a=96.857143$; $b=-17.064|05, c=0.8879| 667 ; d=-0.015815657, e=9.6590909 e-005$ 


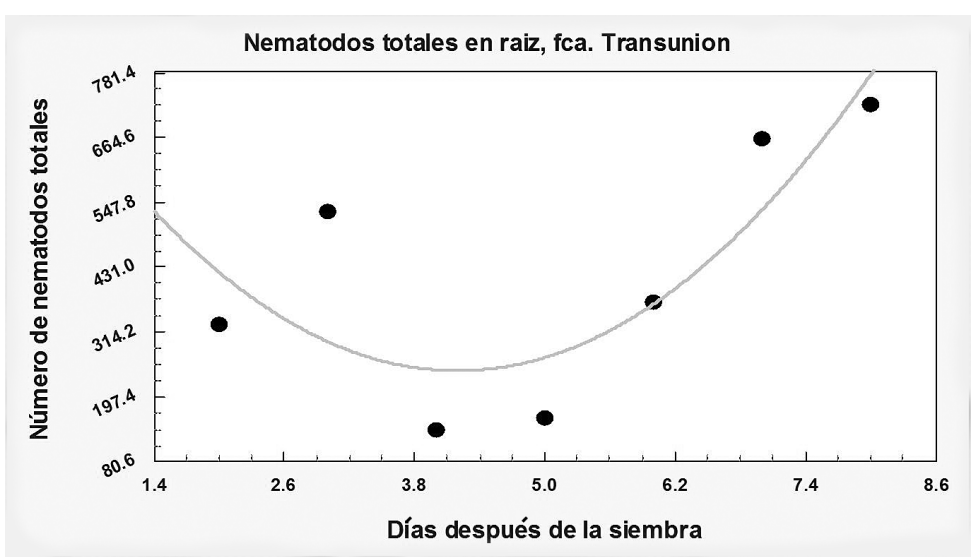

Figura 16. Número de nematodos totales en la raíz en plantaciones convencionales (Transunión).

Ecuación cuadrática: $y=a+b x+c \times 2$. Coeficientes de los datos: $R=0.8$ I; $a=890.57$ I 43; $b=-308.54762, c=36.833333$

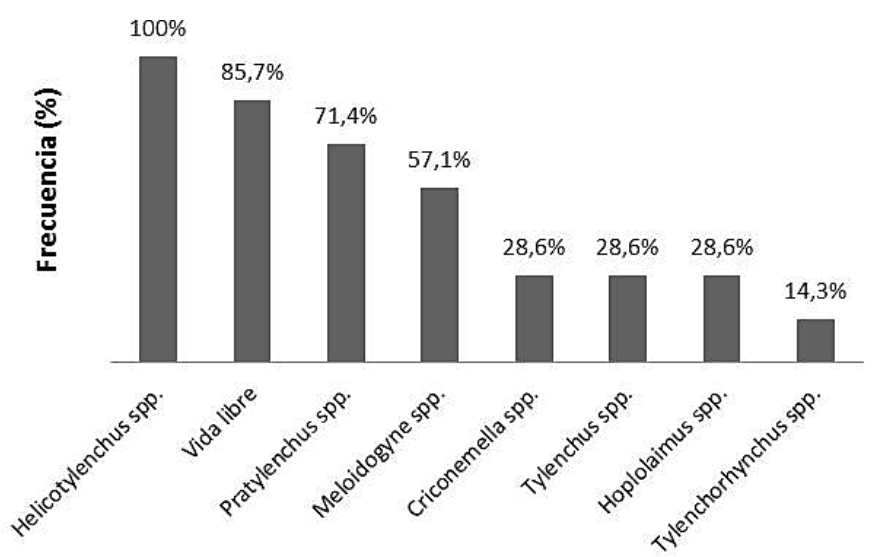

Figura 17. Porcentaje de frecuencia de la presencia por género existente de nematodos del suelo en las plantas de A. comosus híbrido MD-2 de uno a siete meses de edad, bajo las técnicas convencionales de producción en la finca Transunión, Costa Rica, 2006-2008.

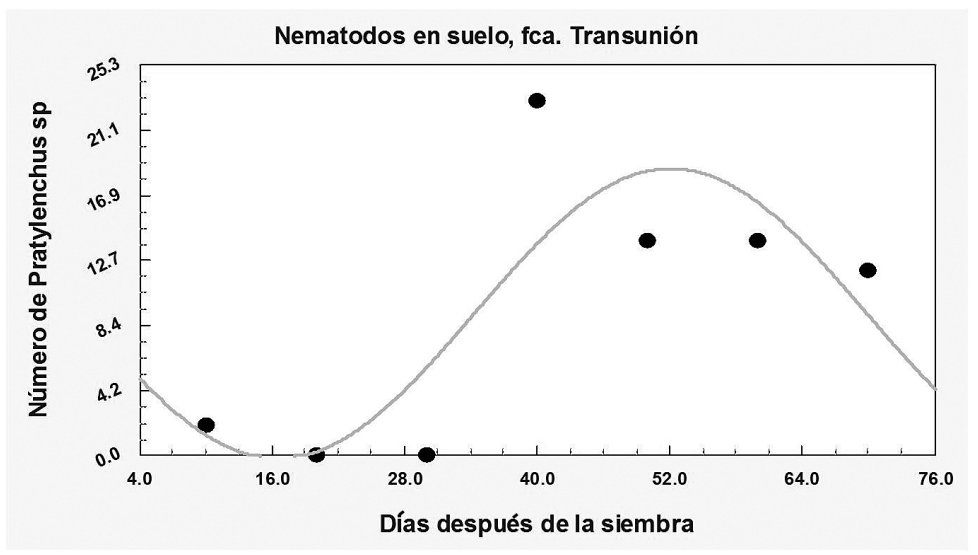

Figura 18. Dinámica de Pratylenchus spp. en el suelo en las plantaciones convencionales (Finca Transunión). Costa Rica. 2006-2008.

Ecuación sinosidal: $y=a+b * \cos (c x+d)$. Coeficientes de los datos: $R=0.81 ; a=9.2149524 ; b=9.407341 ; c=0.08843739$; $d=1.6835264$. 


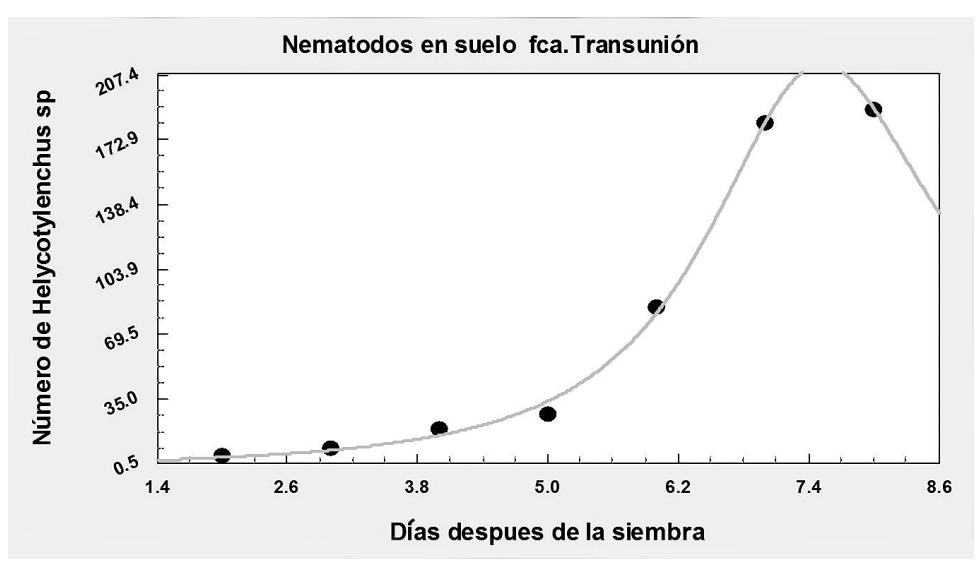

Figura 19. Dinámica de Helycotylenchus spp en el suelo en las plantaciones convencionales (Finca Transunión). Costa Rica. 2006-2008.

Ecuación racional: $y=(a+b x) /(1+c x+d x 2)$. Coeficientes de los datos: $R=0.99, a=0.49752355 ; b=0.8049 \mid 064$; $c=-0.26162284 ; d=0.017651931$

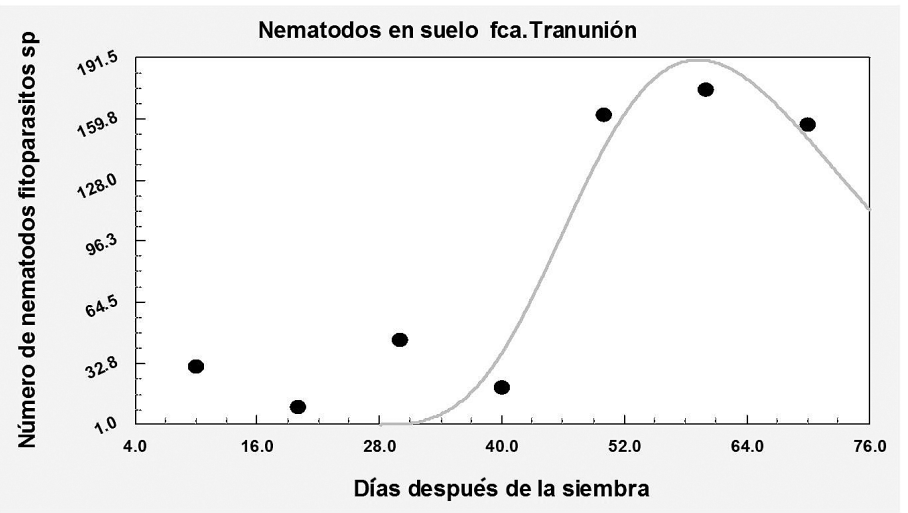

Figura 20. Dinámica de nematodos totales encontrados en el suelo en las plantaciones convencionales (Finca Transunión). Costa Rica. 2006-2008.

Ecuación presión de vapor : $y=\operatorname{Exp}(a+b / x+c \ln (x))$. Coeficientes de los datos: $R=0.93$;

$a=97.76086 ; b=-1077.0828 ; c=-18.210742$

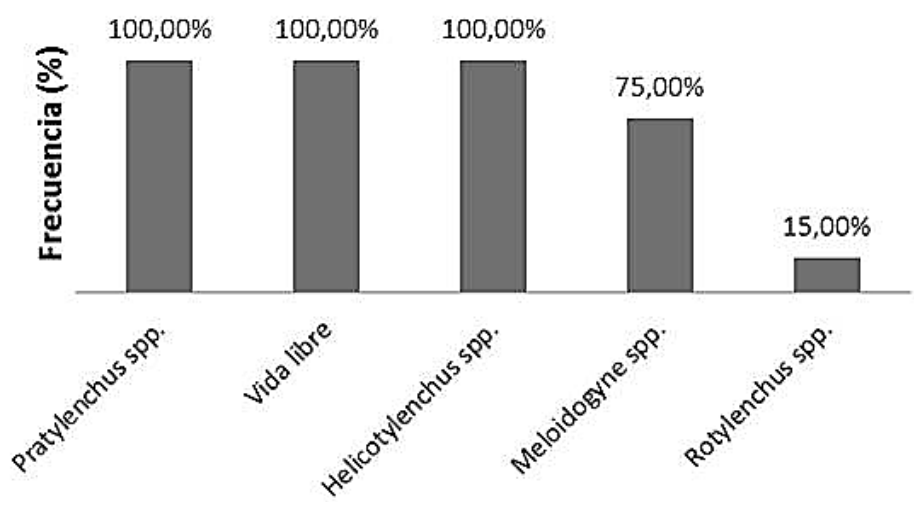

Figura 22. Nematodos parásitos que se encuentran en la finca El Tremedal de San Carlos. Costa Rica. 2006-2008. 
Los modelos de la dinámica de los nematodos en la raíz del cultivo de la piña en plantaciones de cultivo convencional en la Finca El Tremedal se muestran en las figuras 23 y 24.

Al realizar un análisis de los nematodos encontrados en el suelo en la finca el Tremedal se puede observar un comportamiento ascendente en el tiempo y con una tendencia al aumento de las poblaciones tanto de Pratylenchus spp, como de Helicotylenchus spp. Los modelos matemáticos que explican dicho comportamiento se pueden observar en las figuras 25 y 26.

En general, el número de nematodos encontrados en el suelo de todos los géneros fue menor al de los encontrados en el interior de las raíces, aunque la población siempre fue creciente.

Comparación de nematodos en las raíces y el suelo entre los sistemas de cultivos orgánico y convencional en las fincas Corsicana, Transunión y El Tremedal

La comparación entre los nematodos encontrados en el suelo y en la raíz de las plantas, se puede observar en el figura 27.

\section{En las raíces en ambos sistemas}

En la figura 27 se muestra la frecuencia de nematodos en muestras de raíces de plantas conforme a las técnicas de producción orgánica y convencional. Había más nematodos en el manejo orgánico, con nueve géneros en comparación con el tratamiento convencional en el que hubo seis géneros parasitarios y en ambos siempre se presentaron los de vida libre.

En la plantación orgánica, los nematodos fitoparásitos (Helicotylenchus spp.; Pratylenchus spp. y Criconemella spp.) mostraron frecuencias del 100\%, al igual los nematodos de vida libre.

El Helicotylenchus spp. y los nematodos de vida libre se observaron tanto en el manejo orgánico como en el convencional, con una frecuencia de 100. Esto muestra un resultado similar a un estudio realizado por León (2007) en muestras de raíces de las plantas convencionales de piña tomada en diciembre a la edad de doce meses en la finca El Tremedal en San Carlos, en la que el género Helicotylenchus spp. y los nematodos de vida libre, aparecen en todas las épocas de los muestreos que se realizaron.

El género Pratylenchus spp. se observó en las raíces de piña orgánica con una frecuencia de 100\%, mientras que en sistema convencional se presentó con una frecuencia de $85,71 \%$, este género fue identificado por León (2007) con una frecuencia de 90,9\%, en las raíces de las plantas de piña en edades de uno a doce meses.

En las raíces de las plantaciones con el sistema orgánico se observaron los géneros Criconemella spp. y Meloidogyne spp., con un 100\% y un 42,86\% respectivamente; mientras que en el tratamiento convencional y orgánico Meloidogyne spp. se presentó con

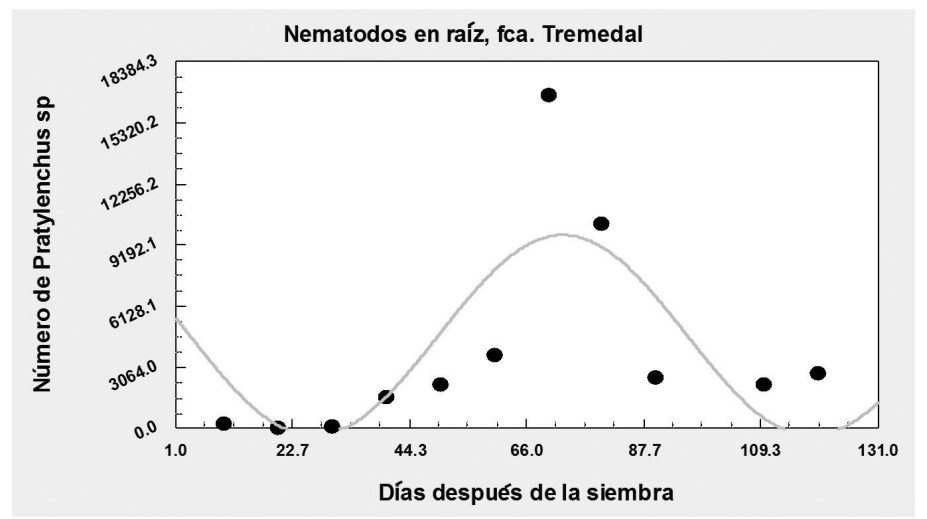

Figura 23. Dinámica de Pratylenchus spp. en la raíz en las plantaciones convencionales en la finca El Tremedal. Costa Rica.2006-2008.

Ecuación de ajuste sinosiodal: $y=a+b * \cos (c x+d)$. Coeficientes de los datos: $R=0.76 ; a=4668.6474 ; \quad b=5032.2794$; $c=0.068244686 ; d=-4.953598$ 


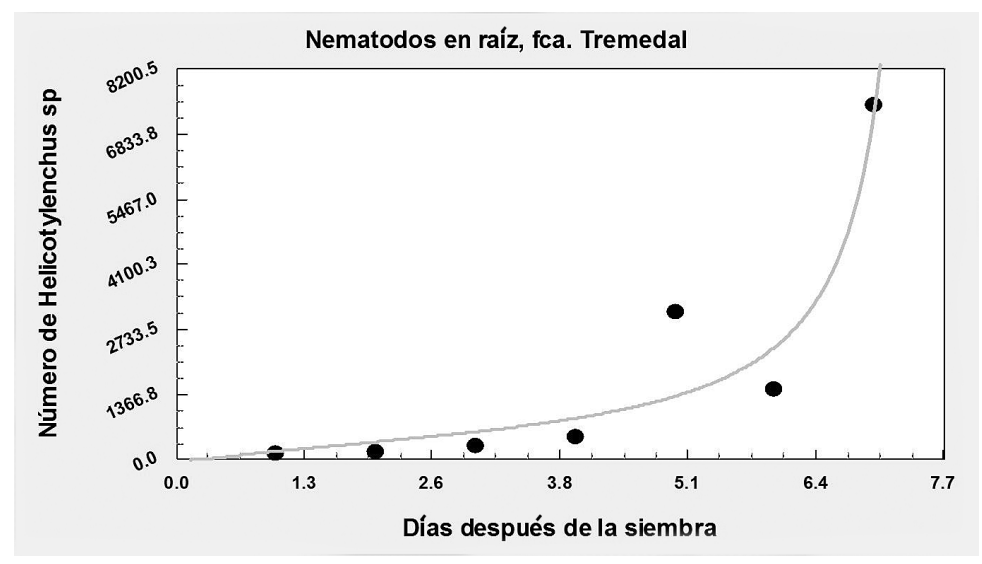

Figura 24. Dinámica de Helicotylenchus spp. en la raíz en las plantaciones convencionales en la finca El Tremedal. Costa Rica.2006-2008.

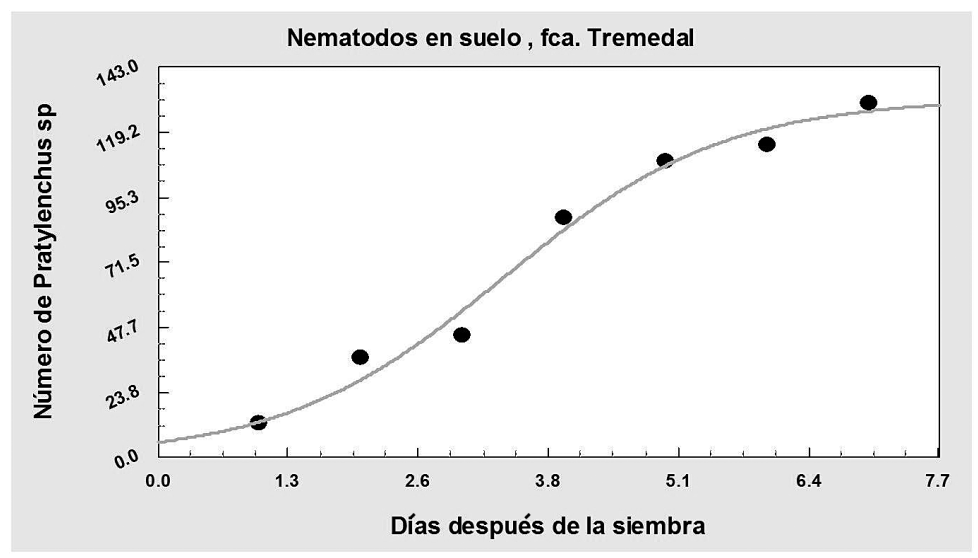

Figura 25. Dinámica de Pratylenchus spp. en el suelo en las plantaciones convencionales (Finca El Tremedal). Costa Rica. 2006-2008.

Ecuación logística: $y=a /(\mid+b * \exp (-c x))$. Coeficientes de los datos: $R=0.99 ; a=131.68023 ; b=22.565455 ; c=0.91735512$

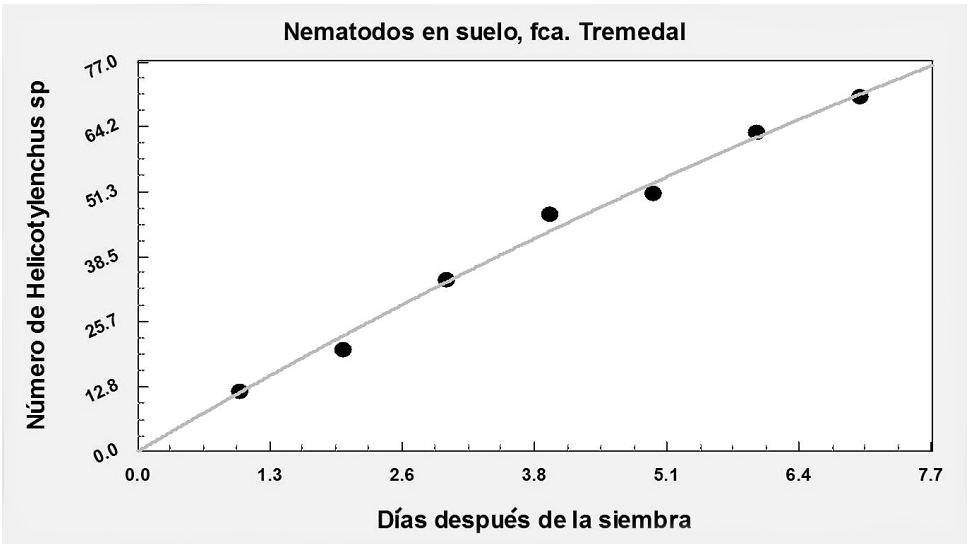

Figura 26. Dinámica de Helicotylenchus spp. en el suelo en las plantaciones convencionales (Finca El Tremedal). Costa Rica. 2006-2008.

Ecuación logística: Ecuación exponencial $y=a(1-\exp (-b x)$. Coeficientes de los datos: $R=0.99 ; a=222.02013$; $b=0.05466 \mid 857$. 


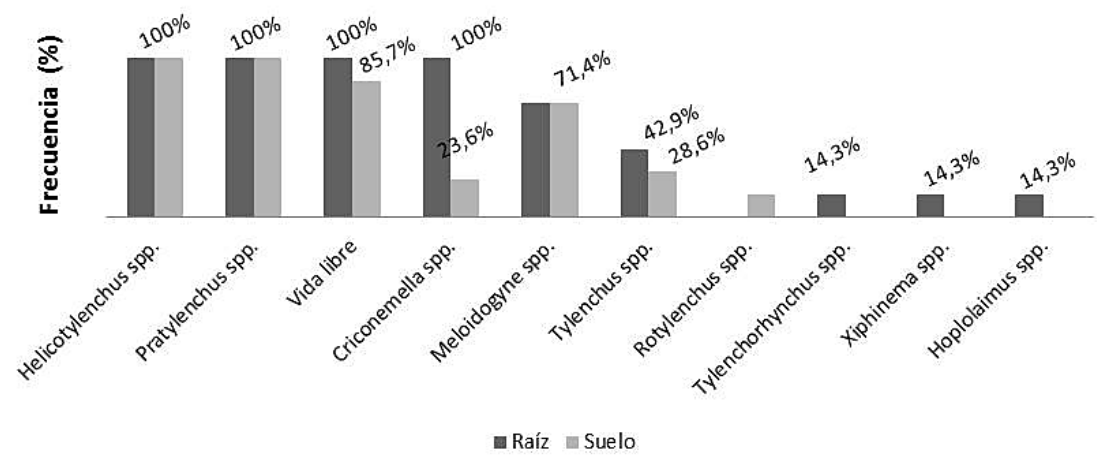

Frecuencia de la presencia de por género en los nematodos del suelo y la raíz de plantas de A. comosus híbrido MD-2 de uno de siete meses de edad, bajo las técnicas convencionales, en Finca Transunion y explotación Sarapiquí. 2008.

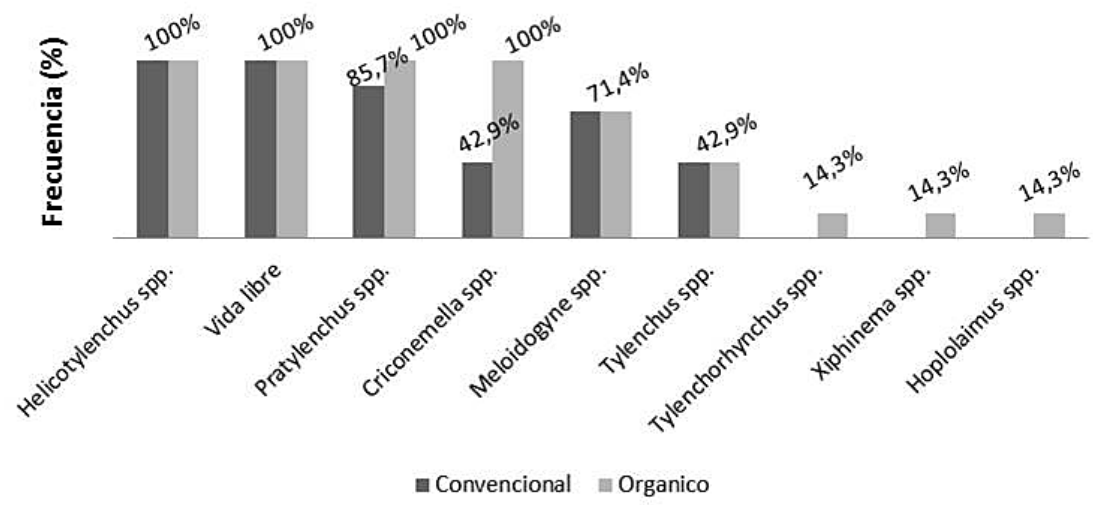

Figura 27. Frecuencia de la presencia de nematodos de género de nematodos en las raíces de plantas de A. comosus híbrido MD-2 de uno a siete meses de edad, en plataciones de producción orgánicas y convencionales en las fincas, El Tremedal,Transunión y Corsicana, Costa Rica, 2006-2008.

una frecuencia similar del 7I,43\%. Según Bafokuzara (1982), en Uganda, en la estación de investigación de Kawanda y Masaka, en muestras de las raíces de la piña del género Meloidogyne spp. se presentó con una frecuencia de $42,9 \%$ y $33,3 \%$.

Comparación de nematodos en el suelo entre los sistemas de cultivos orgánico y convencional en las fincas Corsicana, Transunión y Tremedal

En el suelo cultivado con técnicas orgánicas se presentaron seis géneros parasitarios, mientras que en el suelo con el tratamiento convencional se presentaron siete géneros. En ambos sistemas de producción se observaron un gran número de nematodos de vida libre. En el cultivo de piña en sistema bajo manejo orgánico, dos nematodos fueron los de mayor frecuencia con un 100\% en ambos casos, los cuales fueron, Helicotylenchus spp. y
Pratylenchus spp. A diferencia de las plantas cultivadas bajo el tratamiento convencional en donde sólo apareció el Helicotylenchus spp. con una frecuencia de 100\% (figura 28). El Helicotylenchus spp. fue el género más frecuentemente observado tanto en el sistema orgánico como en el convencional.

Pratylenchus spp. se observó con una frecuencia del 100\% bajo el manejo orgánico, mientras que en suelos cultivados de manera convencional se presentó con una frecuencia de un 71,43\%, León (2007) observó los mismos resultados en su investigación.

El género Meloidogyne spp. se presentó con una frecuencia de 71,43\% en el suelo bajo manejo orgánico, mientras que con el tratamiento convencional se presentó a una tasa de 5I,I4\%. En Uganda, este género presentó frecuencias de $77,1 \%$ y $80,0 \%$ en el suelo cultivado con piña convencional en la estación 


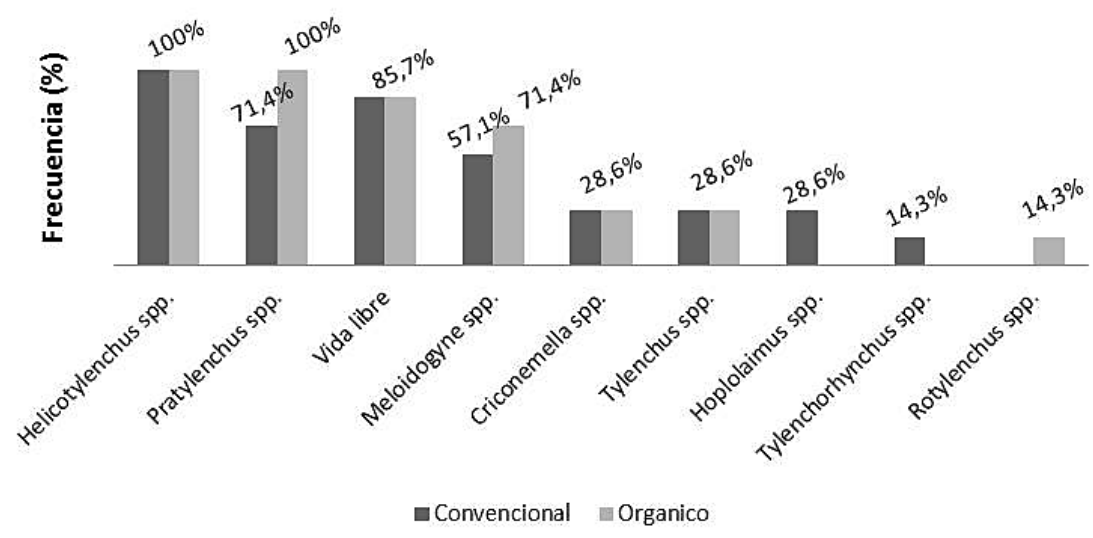

Figura 28. Frecuencia de la presencia por género de los nematodos bajo los sistemas orgánico y convencional en A. comosus híbrido MD-2 en las fincas Corsicana, Transunión y El Tremedal. Costa Rica. 2006-2008.

de investigación de Kawanda y Masaka (Bafokuzara 1982).

El estudio comparativo de la densidad de población de los nematodos encontrados en el suelo y la raíz en plantas bajo técnicas orgánicas y convencionales, de acuerdo con el análisis de varianza, no encontró diferencias significativas para el factor de manejo de la plantación ( $\mathrm{Sig}=903>0,05)$. Esto indica que la densidad de población de los nematodos no se ve influenciada por el manejo de la plantación sea orgánica o convencional.

Sí existen diferencias significativas entre los nematodos (Sig $=0,000<0,05)$ y el tipo de muestra si es de la raíz o del suelo (Sig $=0,000<0,05)$. Por lo tanto, la dinámica y densidad de nematodos sí varía en las poblaciones de nematodos según el tipo de género y de la muestra ya sea de la raíz o del suelo.

El tipo de cultivo orgánico o convencional de las interacciones de plantación - nematodo (Sig = $0,656>0,05)$ y manejo de la plantación - el tipo de muestra (de la raíz y del suelo) (Sig $=0,988>0,05$ ) no tuvo efecto significativo sobre la densidad de la población de los nematodos.

La interacción nematodo por el tipo de muestra (raíz y suelo), presentó diferencia significativas (Sig $=0,000<0,05)$ en la densidad de población de nematodos por lo que este varía según la ubicación.

Dinámica y densidad de la población de nematodos presentes en las raíces de las plantas de piña en orgánica y convencional.

La figura 29 se muestra los valores promedio de individuos que nos permiten observar la densidad de población de nematodos presentes en las raíces de plantas de piña en sistemas de cultivo tanto en sistemas convencionales, como los orgánicos.

El género Pratylenchus spp. en las raíces fue el de la mayor densidad de población tanto en el sistema orgánico como en convencional. En el sistema convencional, con la mayor densidad de población fue de 1.075,22 ind / / $00 \mathrm{~g}$ de raíces y en el orgánico fue de 1009,83 ind / $100 \mathrm{~g}$ de raíces. De acuerdo con León (2007), el género Pratylenchus spp. presenta una densidad de población de 4 219,00 ind / / $00 \mathrm{~g}$

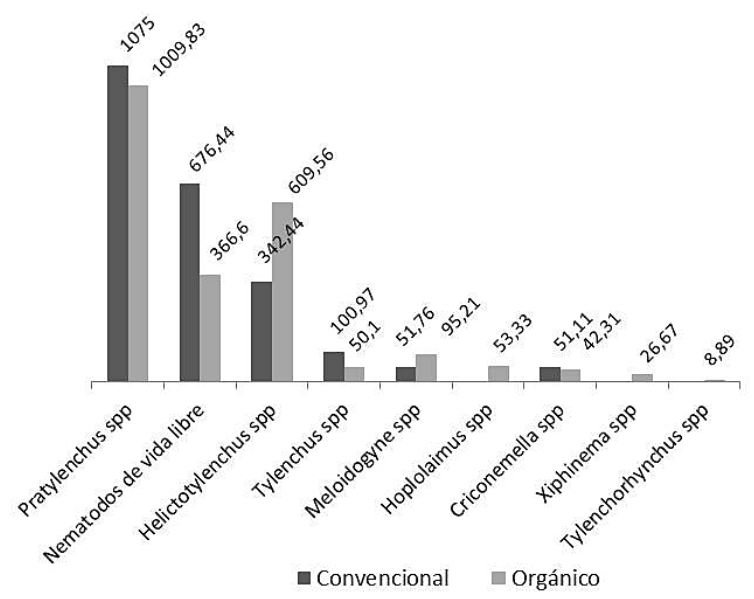

Figura 29. Dinámica y densidad de población de nematodos en las raíces de $A$. comosus híbrido MD-2, en plantas de uno a siete meses de edada, de conformidad con las técnicas convencionales y orgánicos en las fincas Corsicana, Transunión y El Tremedal, Costa Rica, 2006-2008. 
de raíz en el cultivo de la piña en el sistema convencional entre los dos a doce meses de edad.

En las raíces de las plantas bajo manejo orgánico, la mayor densidad de población la presenta el género Helicotylenchus spp. (609,56 ind //00 g de raíces), mientras que en las raíces de las plantas con el sistema convencional fue I 342,44 de ind /g de raíces. La densidad media de población diagnosticada por León (2007) en plantas de piña a las edades de dos a doce meses para el género Helicotylenchus spp., fue 1673.68 ind / $100 \mathrm{~g}$ de raíces.

Meloidogyne spp. presentó su más alta densidad de población en las raíces de las plantas bajo manejo orgánico (95.2I ind/l00 g de raíces), mientras que en los cultivos convencionales tuvo una densidad poblacional de 51,76 ind/ $100 \mathrm{~g}$ de raíces, mientras que León (2007) reportó 85,67ind/ l 00 g de raíces.

Hoplolaimus spp., Tylenchorhychus spp. y Xiphinema spp., se encuentran con muy bajos niveles de presencia en ambos tipos de cultivo.

Densidad de población de los nematodos presentes e el suelo de las plantas en producción orgánica y convencional.

La densidad de población de nematodos en el suelo de las plantas de piña con manejo orgánico y convencional no mostró diferencias significativas entre ellos (figura 30).

A pesar de no existir diferencias, el género Helicotylenchus spp. en labranza convencional mostró una mayor densidad de población en el suelo con relación al cultivo orgánico. Con respecto al número de individuos por unidad de suelo, estos resultados coinciden con lo planteado por León (2007).

Pratylenchus spp. mostró una mayor densidad de población (I 3,78 ind/l 00 g de suelo) en el sistema convencional, comparado con la de manejo orgánico, que fue de 7,56 ind/ lo0g de suelo.

El género Criconemella spp. presentó una mayor densidad de población media en el suelo con el tratamiento convencional ( 1 l,67 ind/l00g) que con el orgánico (5,00 ind/l00g raíz), en donde también fue menor.

Tylenchus spp. se presentó con densidades muy similares tanto en el suelo de las plantas de piña con el sistema orgánico como con el convencional, con
$5,28 \mathrm{ind} / \mathrm{l00g}$ de suelo y 5,33 ind / $00 \mathrm{~g}$ de suelo, respectivamente.

Hoplolaimus spp. apareció solo en el suelo de las plantas de piña con el tratamiento convencional, con una densidad poblacional de 6,67 ind/ I00g de suelo.

El género Rotylenchus spp. solo se pudo observar en suelo bajo manejo orgánico, con una densidad poblacional promedio de 6,67 ind/lo0g de suelo.

El género Tylenchorhychus spp. se observó con una densidad de 6.67 ind/ I00g de suelo, solo en plantaciones de sistema convencional.

Modelos de la dinámica de las poblaciones de nematodos fitoparásitos en la raíz de Ananas comosus híbrido MD-2 en plantaciones orgánicas y convencionales

Los análisis aplicados a las plantaciones en los dos sistemas (orgánico y convencional) no mostraron ningún efecto sobre la densidad de población de nematodos parásitos de plantas (Sig = 535>0,05), ni en tiempo, ni en función de las edades, por lo tanto ambos tienden a ser similares.

Las interacciones entre los factores antes mencionados (edad de la planta, tipo de muestra y manejo orgánico o convencional), no fueron significativamente diferentes.

El estudio de modelos comparativos de la dinámica de los nematodos parásitos en la raíz de las plantas de piña tanto en sistemas orgánico como convencionales se puede observar en la figura 31 .

Aquí se muestra la dinámica de poblaciones y los modelos matemáticos relacionados con el crecimiento total de la población de nematodos fitoparásitos en las raíces de las plantas de piña, teniendo en cuenta la edad y el tipo de manejo orgánico y convencional durante el ciclo de cultivo.

En las raíces de la piña orgánica la densidad de la población en el primer mes de vida fue baja (I53,33 ind/ / $00 \mathrm{~g}$ de raíz), el segundo mes de edad se incrementó a 4II,24 ind/g de raíz, esto significa que el crecimiento es continuo durante todo el ciclo de vida de la plantación bajo este sistema.

Aparentemente, en general existe un antagonismo entre el Meloidogyne spp., el Pratylenchus spp. y el Helicotylenchus spp.,ya que las poblaciones del primero se reducen mucho, con el crecimiento ascendente de los otros dos, en cualquier sistema de cultivo y edad. 


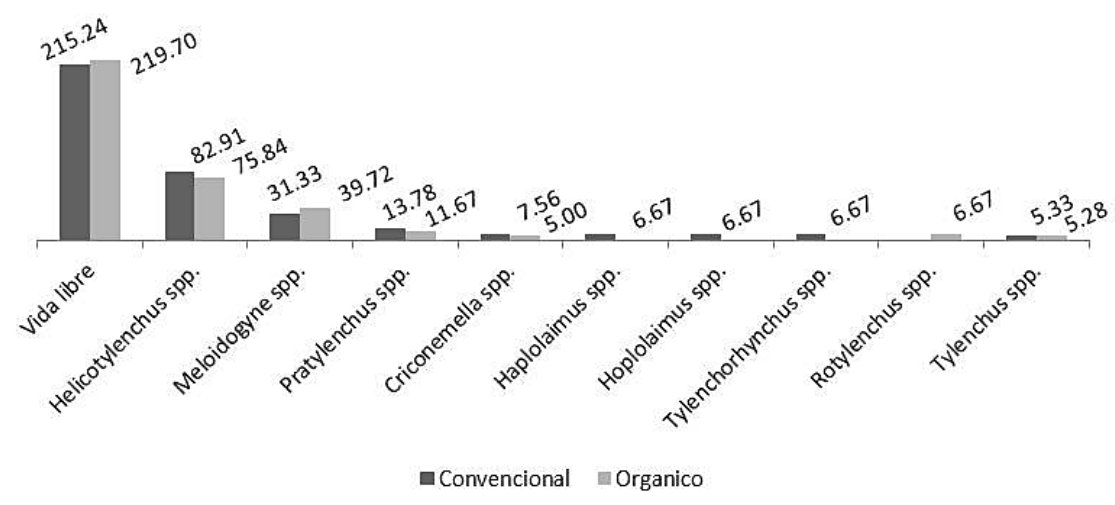

Figura 30. Densidad de población de nematodos en el suelo de plantas de A. comosus híbrido MD-2, bajo las técnicas convencionales y orgánicas en las fincas Corsicana y Transunión.

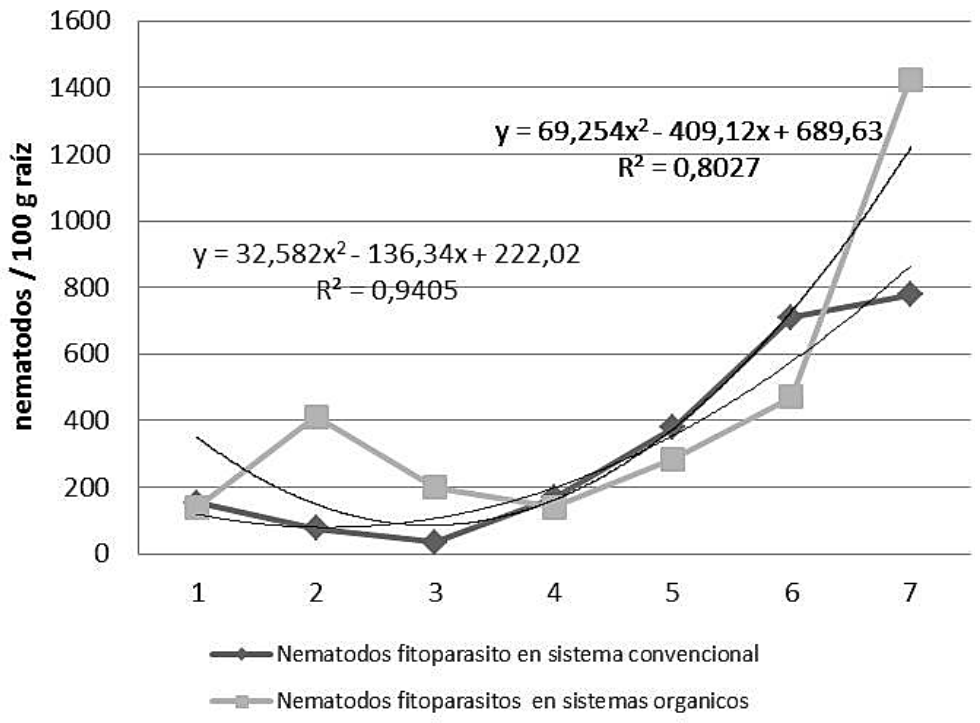

Figura 31. Dinámica de la población y modelos matemáticos para la plantación de nematodos parásitos en función de la edad en las plantas de A. comosus híbrido MD-2, de conformidad con las técnicas convencionales y orgánicos en las fincas Corsicana y Transunión y El Tremedal.

En cuanto a las poblaciones de nematodos en las raíces de las plantas con el tratamiento convencional, el primer mes de edad se observó una densidad media de población de 139,92 ind/l00g de raíz, el segundo mes de edad de plantación, la densidad de población de nematodos disminuyó con un total de 75,86 ind/l00 g de raíz, sin embargo durante los siguientes meses las plantas de piña mostraron poblaciones mayores de nematodos en todos los casos con 168,89 ind/lo0g de raíz, 378,95 ind/l00g de raíz y de 709,42 ind/l00g de raíz. En el último mes de edad presentaron la mayor densidad de población de nematodos parásitos con 776,79 ind/ 100 g de raíz.

Modelos de la dinámica de las poblaciones de nematodos fitoparásitos en suelo de plantaciones orgánicas y convencionales de Ananas comosus híbrido MD-2.

La densidad media de la población de nematodos parásitos en el suelo del cultivo de la piña, orgánica y convencional durante todo el ciclo se muestra en la figura 32. 


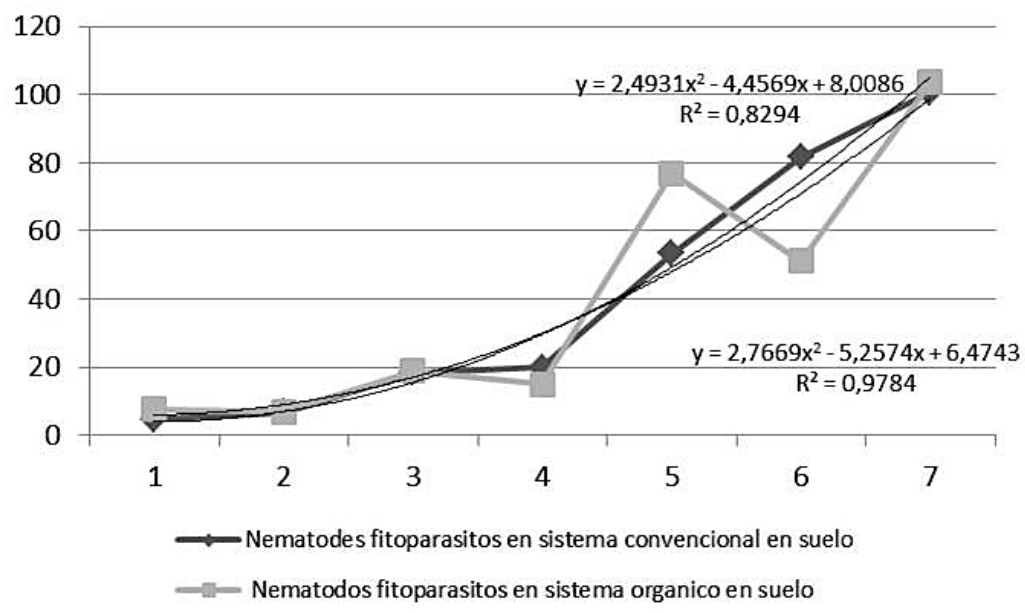

Figura 32. Dinámica de la población y modelos matemáticos para los nematodos en el suelo en plantaciones de A. comosus hibrido MD-2, bajo las técnicas convencionales y orgánicos en las fincas Corsicana, Transunión y El Tremedal, Costa Rica, 2006-2008.

Las poblaciones de nematodos parásitos en el suelo fueron relativamente bajas en comparación con las que se encontraron en las raíces.

En las plantas cultivadas en tierra bajo manejo orgánico, el promedio de la densidad de la población de nematodos en la en el primer y segundo mes de edad fue de 7,78 ind / I00g de suelo $y$ de 7,01 ind $1 / 00 \mathrm{~g}$ de suelo respectivamente. En el tercer mes se produjo la cantidad de 18,89 ind / I00g de suelo y se mostró un aumento en el cuarto y en el quinto mes de edad, cuando se incrementa considerablemente hasta 76,92 ind / I00g de suelo.

Aunque el comportamiento de los nematodos sube y baja según los diferentes meses, siempre se produce un crecimiento de la población total al final del ciclo de cultivo.

En las plantas de tratamiento convencional, la población aumentó durante los meses iniciales y hasta la cosecha, cuando presentó una densidad de población mínima de 4,8I ind/l00g de suelo y una máxima de 100,67 ind/I00g de suelo; para el séptimo mes la población fue creciendo hasta el final de la cosecha.

\section{Conclusiones}

En muestras de raíces de las plantas de A. comosus (piña) en el cultivo orgánico y convencional los géneros de nematodos más frecuentes fueron
Helicotylenchus spp., Pratylenchus spp., Meloidogyne spp. y Criconemella spp., que presentaron una alta frecuencia en relación con la edad y la toma de muestras durante todo el estudio.

En la raíz de las plantas de $A$. comosus en manejo orgánico se encontró una mayor diversidad de nematodos (nueve géneros parasitarios y nematodos de vida libre) que las reportadas en las raíces de las plantas con el tratamiento convencional (seis géneros parasitarios y nematodos de vida libre).

Las muestras de suelo de A. comosus con el tratamiento convencional mostraron una mayor diversidad de nematodos (parásitos y siete géneros de nematodos de vida libre), que la observada en el suelo bajo la planta de manejo orgánico (seis géneros parasitarios y nematodos de vida libre).

Helicotylenchus spp., tanto en el manejo orgánico como en el convencional, se presentó como el nematodo parásito más importante, seguido por Pratylenchus spp.

Los otros géneros están presentes en una proporción menor, como el Criconomella spp., que es un nematodo parásito que tiene la posibilidad de transmitir virus en el cultivo.

En las fincas objetivo del estudio, el comportamiento de los nematodos fue similar, el crecimiento en el tiempo y los modelos matemáticos muestran altos coeficientes de determinación y correlación, 
así como siempre una población en aumento en el tiempo.

No hubo diferencias significativas en las poblaciones de nematodos parásitos en el tipo de agricultura orgánica o convencional, y entre los géneros de nematodos fitoparásitos más importantes encontrados.

En suelos cultivados de A. comosus tanto en fincas orgánicas como convencionales, los nematodos de vida libre tuvieron una densidad de población media alta en todos los tiempos, lo que indica, la buena fertilidad de los suelos y muy buen contenido de materia orgánica.

Estos nematodos parásitos causan graves daños a los cultivos si no se trata a tiempo con las medidas de protección fitosanitaria y la gestión de un buen manejo integrado de plagas.

Los modelos matemáticos usados nos demuestran como se produce en el suelo y en la raíz de las plantas el crecimiento de las comunidades de nematodos fitoparásitos, a prtir de los cuales se podrán hacer predicciones de estos para las mismas condiciones en que se realizó este estudio. A su vez le permitirá a los investigadores poder usar esta herramienta para valorar crecimientos poblacionales en el tiempo y como es lógico su predicción.

\section{Recomendaciones}

Se recomienda llevar a cabo estudios dirigidos a la determinación de umbrales de daños específicos y su repercusión económica sobre el cultivo, teniendo en cuenta el efecto de las poblaciones de nematodos fitoparásitos sobre el rendimiento y los costos de control.

También se recomiendan realizar estudios específicos sobre Helicotylenchus spp.. y Pratylenchus spp..., y sus efectos sobre la producción, así como la determinación de los niveles de población perjudiciales para la piña a través de escalas valorativas.

\section{Bibliografia}

Bafokuzara, N.D. (1982). Nematodes associated with pineapple in Uganda. Kawanda Reserch Station. Masaka Cooperative Union, Kampala. Nematropica (I2) |.
Brenes, S. (2007). Caracterización vegetativa y productiva del cultivar MD-2 de piña (Ananas comosus) bajo las condiciones climáticas de Turrialba. (en línea). Consultado el 12 de marzo 2009. Disponible en: http://intersedes.ucr.ac.cr/ pdfs_I | / | -art_03.pdf.

Castro, Z. (1994). Cultivo de la piña. En: Gonzalo C., E. Atlas Agropecuario de Costa Rica. San José: Editorial Costa Rica.

Castro, Z. (2000). Estudio de la actividad productora de piña (Ananas comosus (L.) Merr y comportamiento del mercado interno en Costa Rica. San Carlos, Costa Rica. 64 pp. Informe técnico Escuela de Agronomía.

Castro J., Z. (2004). Guía para el cultivo de piña (Ananas comosus) (L) Merr. Instituto Tecnológico de Costa Rica, Sede Regional San Carlos, Escuela de Ingeniería en Agronomía. 123 pp.

Creación del Fondo para el Desarrollo Integral del Cultivo de Piña y Mitigación del Impacto Ambiental. (2005). Proyecto de Ley. Asamblea Legislativa de Costa Rica. (en línea). Consultado en abril de $201 \mathrm{I}$. Obtenido desde: http://www. comex.go.cr/difusion/comunicados/CP-66l.htm.

Esquivel, A. (2005). Manual de identificación de géneros de nematodos importantes en Costa Rica. Heredia, CR: Universidad Nacional. 50 pp.

Hernández H., R. (1998). Los nematodos parásitos de la piña. Opciones para su manejo. La Habana: Instituto de Investigaciones en Fruticultura Tropical.

Jesse R. C. (1976). Nematodos de los vegetales. Su ecología y control. Editorial SERBIULA (sistema Librum 2.0) Puerto Rico.

Jessé, R. C.(1978). Fitonematología tropical.Estación Experimental Agrícola de la Universidad de Puerto Rico 7(43): 205-217. Editorial SERBIULA (sistema Librum 2.0) Puerto Rico.

Lara, J. (1984). Informe de resultados de muestreo nematológico del cultivo de piña en Panamá Oeste. IDIAP. (sin publicar).

Luc, M., Sikora, R.A. \& Bridge, J. (2005). Plant parasitic nematodes in subtropical and tropical agriculture. Nematode Parasites of Pineapple. 2 ed. Massachusetts: CAB International.

Quesada, M. \& Barboza, R. (1999). Distribución espacial de Helicotylenchus spp. en el suelo de una plantación de piña (Ananas comosus) en la zona norte de Costa Rica. Agronomía Costarricense 23(1).

Radewald \& Takeshita (1964). Desiccation studies on five species of plant-parasitic nematodes of Hawaii. Phytopathology 54: 903-904.

Rich, J. \& Hendley, S. (2003). Introduction to Plant Parasitic Nematodes and Their Management. (en línea). Entomology and Nematology Department University of Florida, US. (Consultado el 4 abril 2009). Obtenido desde: http://www. ontaweb.org/.

Román, J. (1978). Fitonematología tropical. Nematodos de la piña (Ananas comosus) (L) Merr. Estación Experimental Agrícola de la Universidad de Puerto Rico. 
Sasser J., N. (1989). Plant-Parasitic Nematodes: The Farmer's Hidden Enemy. Department of Plant Pathology Norht Carolina State University. I 5 pp.

Tarjan, A. (1967). Some plant nematode genera associated with citrus and other crops in Costa Rica and Panamá. Turrialba 17(3):280-283.

Tarté, R. (1970). Reconocimiento de nematodos asociados con diversos cultivos en Panamá. Turrialba 20(4): 40 I-406.

\section{Reconocimiento}

Los autores agradecen a los colegas del laboratorio de Nematología, del Instituto Tecnológico de Costa Rica, Sede Regional de San Carlos, a la Vicerrectoría de investigación y Extensión de nuestra Institución, al Ministerio de Ciencia y Tecnología, así como al Consejo Superior de Investigaciones Cientíicas, ambas de Costa Rica, por el apoyo recibido para participar en el "Cuarta conferencia Internacional sobre Agricultura celebrada en Atenas, Grecia, los días |8-2| de julio del 20। I. A su vez al Consejo Nacional de Rectores por el apoyo al financiamiento de parte de este proyecto.

\section{Acknowledgment}

We wish to thank through this conduit colleagues Nematology Laboratory, the Vice-Rector for Research and Extension of the Technological Institute of Costa Rica, the Ministry of Science and Technology (MICIT) and the National Research Council (CONICIT) Costa Rica both institutions for the support provided for conducting this research and its presentation in the "4th Annual International Conference on Agriculture", I 8-2 I July 20 I I, Athens, Greece. 